\title{
Plant Secondary Metabolite Biosynthesis and Transcriptional Regulation in Response to Biotic and Abiotic Stress Conditions
}

\author{
Rahmatullah Jan ${ }^{1,2,+}\left(\mathbb{D}\right.$, Sajjad Asaf ${ }^{3,+}+\mathbb{D}$, Muhammad Numan ${ }^{4}$, Lubna ${ }^{5}$ and Kyung-Min Kim ${ }^{1,2, * \mathbb{D}}$ \\ 1 Division of Plant Biosciences, School of Applied Biosciences, College of Agriculture \& Life Science, \\ Kyungpook National University, Daegu 41566, Korea; rehmatbot@yahoo.com \\ 2 Costal Agriculture Research Institute, Kyungpook National University, Daegu 41566, Korea \\ 3 Natural and Medical Science Research Center, University of Nizwa, Nizwa 616, Oman; \\ sajadasif2000@gmail.com \\ 4 Laboratory of Molecular Biology and Biotechnology, Department of Biology, University of North Carolina at \\ Greensboro, Greensboro, NC 27412, USA; mnuman@bs.qau.edu.pk \\ 5 Department of Botany, Garden Campus, Abdul Wali Khan University, Mardan 23200, Pakistan; \\ lubnabila168@gmail.com \\ * Correspondence: kkm@knu.ac.kr \\ + These authors contribute equally to this manuscript.
}

Citation: Jan, R.; Asaf, S.; Numan,

M.; Lubna; Kim, K.-M. Plant

Secondary Metabolite Biosynthesis and Transcriptional Regulation in Response to Biotic and Abiotic Stress Conditions. Agronomy 2021, 11, 968 https://doi.org/10.3390/ agronomy 11050968

Academic Editor: Pilar Soengas

Received: 19 April 2021

Accepted: 11 May 2021

Published: 13 May 2021

Publisher's Note: MDPI stays neutral with regard to jurisdictional claims in published maps and institutional affiliations.

Copyright: (c) 2021 by the authors. Licensee MDPI, Basel, Switzerland. This article is an open access article distributed under the terms and conditions of the Creative Commons Attribution (CC BY) license (https:/ / creativecommons.org/licenses/by/ $4.0 /)$.

\begin{abstract}
Plant secondary metabolites (SMs) play important roles in plant survival and in creating ecological connections between other species. In addition to providing a variety of valuable natural products, secondary metabolites help protect plants against pathogenic attacks and environmental stresses. Given their sessile nature, plants must protect themselves from such situations through accumulation of these bioactive compounds. Indeed, secondary metabolites act as herbivore deterrents, barriers against pathogen invasion, and mitigators of oxidative stress. The accumulation of SMs are highly dependent on environmental factors such as light, temperature, soil water, soil fertility, and salinity. For most plants, a change in an individual environmental factor can alter the content of secondary metabolites even if other factors remain constant. In this review, we focus on how individual environmental factors affect the accumulation of secondary metabolites in plants during both biotic and abiotic stress conditions. Furthermore, we discuss the application of abiotic and biotic elicitors in culture systems as well as their stimulating effects on the accumulation of secondary metabolites. Specifically, we discuss the shikimate pathway and the aromatic amino acids produced in this pathway, which are the precursors of a range of secondary metabolites including terpenoids, alkaloids, and sulfur- and nitrogen-containing compounds. We also detail how the biosynthesis of important metabolites is altered by several genes related to secondary metabolite biosynthesis pathways. Genes responsible for secondary metabolite biosynthesis in various plant species during stress conditions are regulated by transcriptional factors such as WRKY, MYB, AP2/ERF, bZIP, bHLH, and NAC, which are also discussed here.
\end{abstract}

Keywords: alkaloids; bioactive; deterrent; herbivores; salinity; terpenoids

\section{Introduction}

Compounds produced by plants are categorized into primary and secondary metabolites (SMs). Primary metabolites, such as carbohydrates, lipids, and proteins, are directly involved in plant development and growth. In contrast, SMs are multifunctional metabolites that are typically involved in plant defense and environmental communication [1]. Furthermore, they are associated with plant color, taste, and scent. Critically, they are also involved in the responses of plants to stress. For example, SMs are involved in the termination of infection, whether biotic- or abiotic-related [2]. Along with their importance in biotic stress tolerance, plant SMs are also involved in mitigating abiotic stresses such as temperature, drought, salinity, and UV light stresses [3]. When faced with certain biotic 
and abiotic stresses, plants can reduce morphological traits such as the number of leaves or branches, leaf area, height, and root volume [4]. Indeed, plants have a diverse array of defense mechanisms that allow them to cope with stress conditions, mitigate abiotic stress at the metabolomic level, and enhance SM accumulation during stress.Threat signals are recognized by plants' receptors and sensors, which enable defensive responses in order to protect them from these stresses. The accumulation of secondary metabolites is one of the responses (Figure 1).Transcriptional factors (TFs) play a role in plant defense control by detecting stress signals and directing downstream defense gene expression. Similarly, the plant's survival, durability, and productivity are all dependent on increased synthesis of secondary metabolites, known as elicitation. Various biotic (fungi, bacteria, etc.) and abiotic (exogenous hormones) elicitors are used to enhance secondary metabolites production in plants to protect them from stress stimuli (Figure 1).

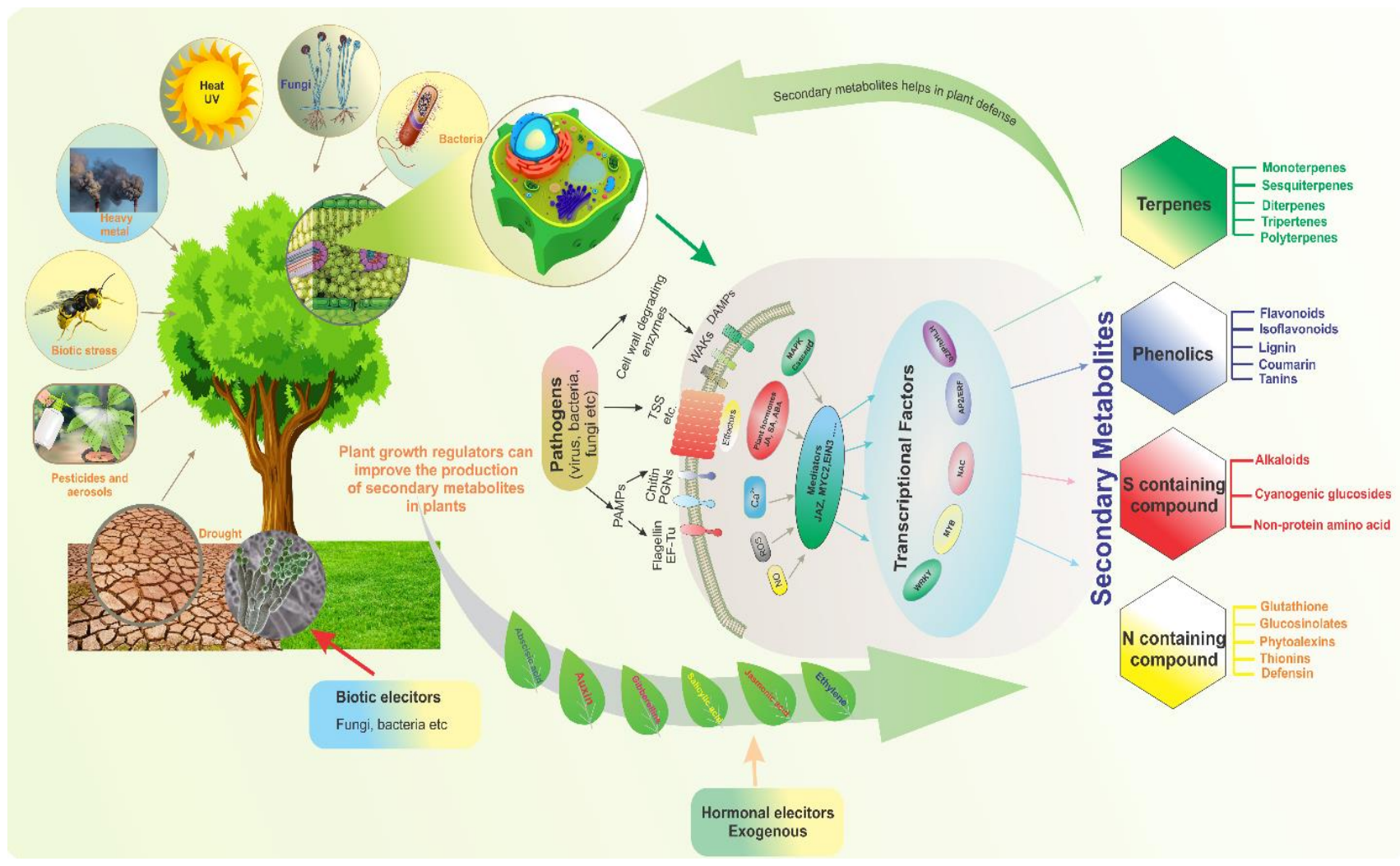

Figure 1. Diverse biotic and abiotic stresses affect plant growth and development; plants adopt various strategies and defense mechanisms to mitigate these stresses. To illustrate the modulation of secondary metabolism by various transcription factors, which are regulated by complicated upstream signaling pathways in response to stress, four plant secondary metabolite types involved in various modes of resistance are exemplified.

Plants produce SMs through several metabolic pathways that effectively respond to stress conditions. These pathways are initiated from primary metabolite pathways, which produce the ultimate precursors of SMs. The shikimate pathway is the initial pathway for biosynthesis of aromatic amino acids; it is activated in stress conditions to produced tryptophan, tyrosine, and phenylalanine, which further enhance SM biosynthesis [5]. Different SMs accumulate conditionally in various plant parts depending on the stress condition. For example, phytoalexins have antimicrobial activities against phytopathogens and accumulate at high levels in leaves [6]. In addition to their antimicrobial properties, some SMs participate in the construction of polymeric barriers to pathogen penetration. In this regard, plants have a sophisticated recognition and signaling system that enables rapid recognition of pathogen attack and can initiate a dynamic defensive response. Accumulation of 
SMs in response to stress conditions is regulated at the molecular level by various genes and transcription factors (TFs) including those of the phytohormonal pathway (Figure 1). Among all TFs, only a few modulate stress responses by mediating SM accumulation. This review is based on current knowledge of TF and gene-mediation of SM accumulation in response to stress conditions).

\section{Biosynthetic Pathway of SMs}

The precursors of metabolites are essentially produced in the Krebs cycle and shikimate pathway. The proposed SM biosynthesis pathway is shown in Figure 2. Primary metabolites are the critical precursors of SMs. Primary and SMs can be distinguished based on their chemical structure, function, and distribution in plants. The fundamental biosynthetic pathways of metabolites are conserved in the majority of plants, with most primary metabolites found in every tissue type. The maintenance of this metabolic core has led to the occurrence of a limited number of fundamental metabolic frameworks. Frequent glycosylation, methylation, hydroxylation, acylation, oxidation, phosphorylation, and prenylation, as well as fewer chemical alterations due to tailoring of enzymes, causes a wide range of modifications in basic structures. Based on biosynthesis pathways, SMs can be divided into three main groups: phenolic compounds synthesized in the shikimate pathway, terpenes synthesized in the mevalonic pathway, and nitrogen-containing compounds synthesized in the tricarboxylic acid cycle pathway [7].

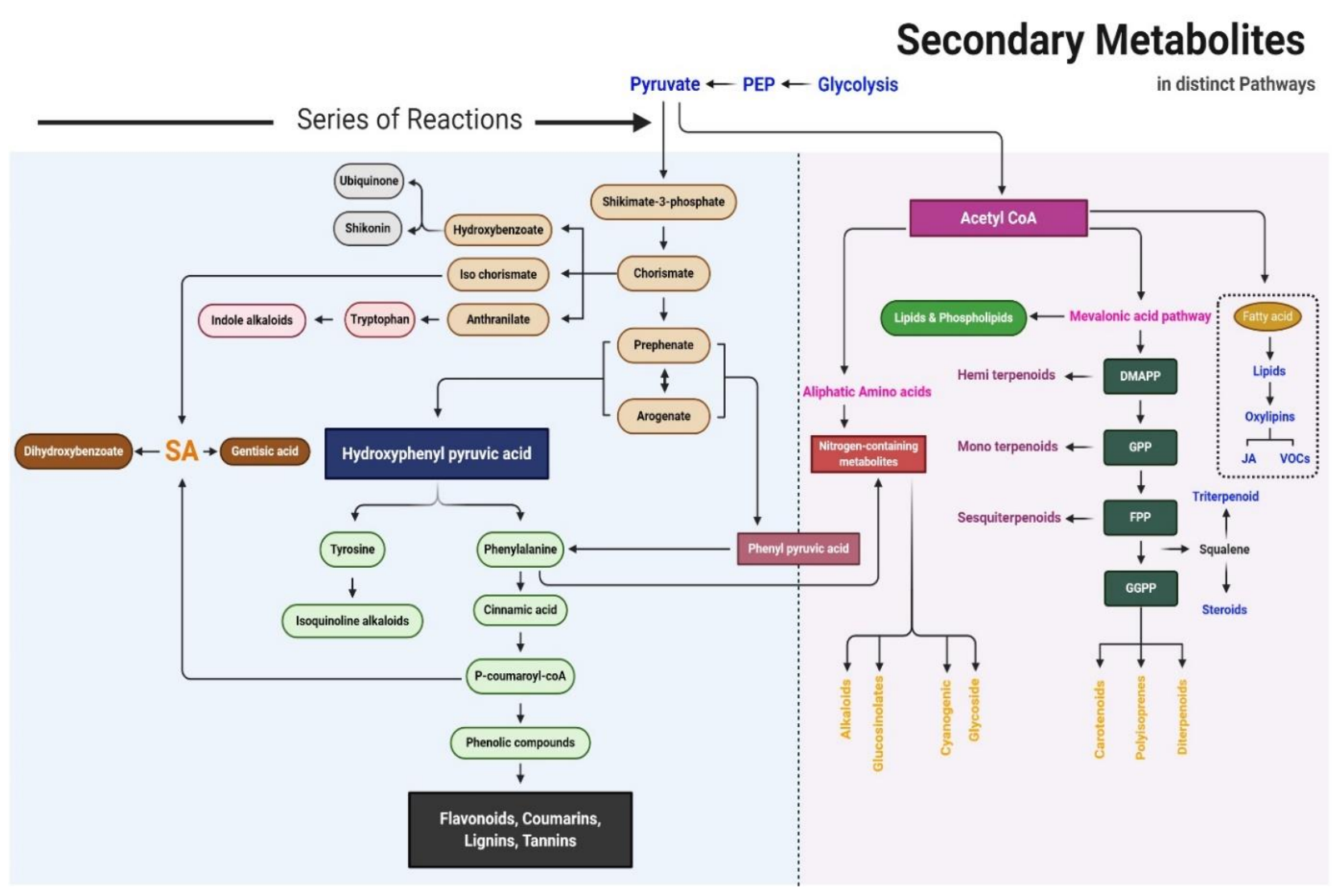

Figure 2. Schematic of the secondary metabolite biosynthesis pathway.

Shikimic acid, the precursor of the shikimate pathway, is produced from a combination of phosphoenolpyruvate (from the glycolytic pathway) and erythrose 4-phosphate (from the pentose phosphate pathway). Phenylalanine, tyrosine, and tryptophan are produced in the shikimate pathway; these are the building blocks of protein synthesis and common precursors for plant SMs such as phenolics and nitrogen-containing compounds [6]. Phenylalanine is the common precursor of flavonoids, lignans, lignins, condensed tannins, and 
phenylpropanoid/benzenoid volatiles; tyrosine further produces isoquinoline alkaloids, pigment betalains, and quinones (e.g., tocochromanols and plastoquinone); and tryptophan is the precursor of alkaloids, phytoalexins, indole glucosinolates, and the plant hormone auxin [8].

Seven steps are involved in the shikimate pathway to generate the end-product chorismate. In the first step, phosphoenolpyruvate and erythrose-4-phosphate are condensed to 3-deoxy-o-arabino-heptulosonate 7-phosphate (DAHP), which can formally be considered a 2-deoxy-D-glucose-6-phosphate derivative. In the second step, DAHP is exchanged with 3-dehydroquinate synthase to form the highly substituted cyclohexane derivative 3-dehydroquinate. The remaining steps in the shikimate pathway serve to add side chains and two of the three double bonds that convert this cyclohexane into a benzene ring (the hallmark of aromatic compounds). The third and fourth reaction in the shikimate pathway includes the dehydration of dehydroquinate to 3-dehydroshikimate, which is catalyzed by 3-dehydroquinate dehydratase (DHD), and the reversible reduction of 3-dehydroshikimate into shikimate using NADPH, which is catalyzed by shikimate dehydrogenase (SDH). DHD and SDH not only catalyze these respective reactions but are also part of the AROM complex in fungi. Furthermore, they are monofunctional in Escherichia coli but bifunctional in plants in the fused form of the DHD-SDH enzyme. The fifth step of the shikimate pathway is the formation of shikimate 3-phosphate. In this step, shikimate kinase catalyzes the phosphorylation of shikimate at the C3 hydroxyl group using ATP as a substrate. The sixth and seventh steps are catalyzed by 5-endolpyruvylshikimate 3-phosphate synthase (EPSP) and chorismate synthase, respectively. EPSP (also known as 3-phodphoshikimate 1-carboxyvinyltransferase) regulates the next to last step of the shikimate pathway by transferring the enopyruvyl moiety of phosphoenolpyruvate into shikimate 3-phosphate. Chorismate synthase is the final enzyme to participate in the shikimate pathway; it catalyzes the conversion of EPSP into chorismate, which is the precursor of SMs. In this final step, 1,4-anti-elimination of the 3-phosphate and C6-pro-R hydrogen from EPSP introduces the second double bond in the ring to produce chorismate. In higher plants, chorismate is the precursor of tryptophan, tyrosine, phenylalanine, salicylate, phylloquinone, and folate; it is regulated by enzymes such as chorismate mutase, iso-chorismate synthase, anthranilate synthase, and aminodeoxychorismate synthase [8].

\section{Overview of SMs}

\subsection{Phenolic Compounds}

Phenolic compounds, a group of SMs that are ubiquitous in plants and plant-derived foods, are essential for plant defense against parasites and pests [9]. They are characterized by their structure, which includes a minimum of one phenol ring. They are highly structurally diverse, containing simple molecules (e.g., vanillin, gallic acid, and caffeic acid) and polyphenols (e.g., stilbenes, flavonoids, and polymers). Phenolic compounds are usually present in plants in soluble or bound forms but they can also be categorized into subgroups according to their chemical structures. Soluble phenolic compounds are commonly synthesized in the endoplasmic reticulum and preserved in vacuoles, whereas bound phenolic compounds are produced by the transformation of soluble phenolic compounds to the cell wall, where they conjugate with the molecules of the cell wall through glycosidic and ester bonds [10]. General structure for each group of phenolic compound is presented in supplementary Figure S1.

\subsubsection{Coumarin}

Coumarins (2H-benzopyran-2-one), a class of simple phenolic compounds consisting of a large phenolic substance produced from the fusion of a benzene ring and $\alpha$-pyrone rings, are widespread in vascular plants. They were initially reported in the tonka bean (Dipteryx odorata) and subsequently reported in around 150 different species from 30 families [11]. About 1300 coumarins have been identified in plants as SMs; these function in a variety of capacities in many plants, typically in plant defense [12]. Along with defensive 
effects on herbivores and fungi, coumarins have antimicrobial activity due to a specific bioactive group of molecules. They are distributed in all parts of plants; however, they are found at the highest levels in seeds [13]. Coumarins are naturally categorized into six types based on their chemical structure: simple (e.g., fraxin), furano (e.g., imperatorin), dihydrofurano (e.g., anthogenol), linear-type (e.g., grandivittin), phenyl (e.g., inophyllum), and bicoumarins (e.g., dicoumarol) [11].

\subsubsection{Lignin}

After cellulose, lignin is the most abundant biopolymer on earth and contributes to about $30 \%$ of the organic carbon in the biosphere. Lignin is one of the complex racemic heteropolymer components of the cell wall; it has a high molecular weight and is produced by the oxidative combinatorial coupling of primarily three p-hydroxycinnamoyl alcohol monomers (the so-called monolignols) [14]. Lignin is an important SM and broadly contributes to plant growth, development of tissues and organs, loading resistance, and biotic and abiotic stress tolerance. Lignification is a protective strategy of plant against pathogen and herbivores as it causes physical toughness to plant tissues which result the plant tissue non-digestible to insects and other herbivores.

\subsubsection{Furanocoumarins}

Furanocoumarin compounds are known for their phytotoxicity and are primarily found in species from Apiaceae and Rutaceae. Partly, furanocoumarins are synthesized in the phenylpropanoid and mevalonate pathways via the coupling of dimethylallyl pyrophosphate and 7-hydroxycoumarin. Usually, these compounds become toxic when they are activated by UV-A radiation, which leads to the activation of a higher electron energy state. Because of this activation, furanocoumarins enter the double helix of DNA and bind to pyrimidines; this causes cell death due transcription blockage and also possess mutagenic and carcinogenic properties [15]. Furanocoumarins also inhabit feeding behavior and physiological development of various insects [16]. It is found mostly in plant roots leaves and fruits and store in the form of essential oil. It has the great ability to sensitize cells to sunlight, and visible and ultraviolet light [17].

\subsubsection{Flavonoids}

Flavonoids, a diverse group of low-molecular-weight phenolic compounds, are found in the form of phytonutrients in the human diet and are ubiquitous in the plant kingdom (to date, $\sim 8000$ flavonoid molecules have been reported). They comprise one of the most characteristic classes of SMs in higher plants. The chemical structure of flavonoids usually consists of a 15-carbon skeleton with a phenyl ring and heterocyclic ring. Flavonoids have vital functions in plant defense and pigmentation systems. They also have wide range of health-promoting activities and a crucial ingredient of pharmaceutical, medicinal, and cosmetic products. For example, they can alter key cellular enzymatic functions because of their anti-inflammatory, antioxidative, anticarcinogenic, and antimutagenic properties, and they are efficient inhibitors of numerous enzymes [18]. Given the importance of flavonoids to plant life, they are classified in Figure 3.

\subsubsection{Isoflavonoids}

Isoflavonoids, a large group of diphenolic compounds classically defined as dietary antioxidants, include isoflavones, isoflavans and pterocarpans. They consist of a phenyl ring combined with a heterocyclic $\mathrm{C}$-ring and another B-ring fused at the $\mathrm{C} 3$ position (unlike flavonoids, in which the B-ring is placed at the C2 position) [19]. Isoflavonoids are present in a limited group of plants and mostly found in leguminous species. They are naringenin derivatives that are important for nitrogen-fixing nodule formation and therefore the promotion of symbiotic rhizobia [20]. During plant-microbe interactions, isoflavonoids may be involved in the development of phytoalexins [21]. Some isoflavonoids have been reported to be present in microbes. 


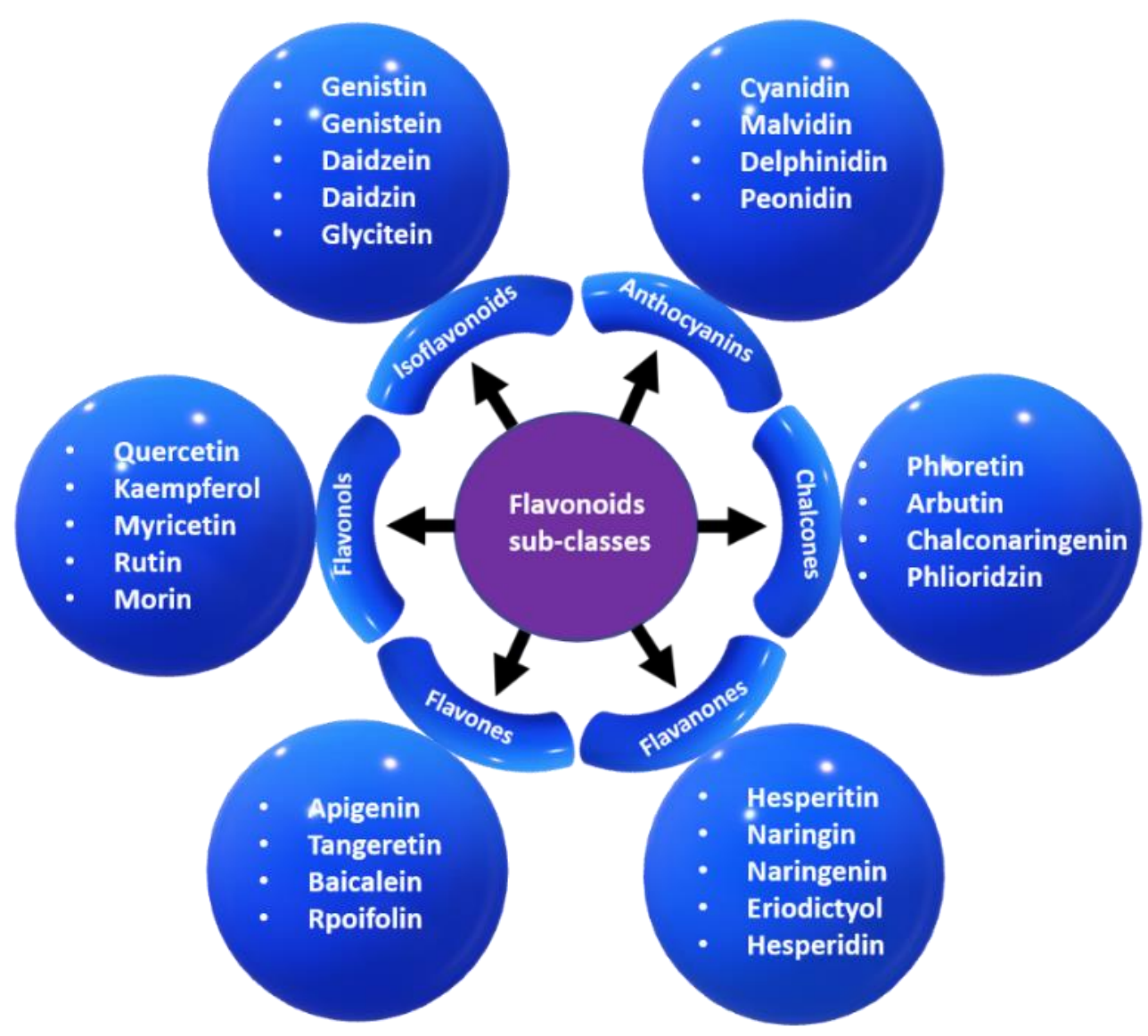

Figure 3. Classification of plant flavonoids.

\subsubsection{Tannins}

Tannins are the third essential group of phenolic compounds. They are rich in oligos and polymers and can make complexes with proteins, minerals, cellulose, and starch. Tannins can be divided into two subgroups, condensed and hydrolysable tannins, which have molecular masses of 600-3000. In general, tannins are toxins that have the potential to affect the growth and survival of most herbivores; therefore, they act as repellents to various grazing animals [15]. Tannins such as chlorogenic acid and protocatechuic acid also play major roles in the resistant of plants to various diseases. Environmental factors, such as excessive $\mathrm{CO}_{2}$ in atmosphere, high temperature, light conditions, and nutrient variation, can significantly alter the accumulation of tannins in the plants [22].

\subsection{Terpenes}

Terpenes or terpenoids, the major class of SMs in plants, are formed from the derivatives of glycolytic or acetyl CoA intermediates. They are lipid-soluble and have vast structural diversity (more than 50,000 different structures) [23]. Terpenes are the essential building blocks of various complex phytohormones, sterols, and pigments, and they are primarily responsible for their aromas and physiological effects. Although some terpenes have a pleasant aroma and act as pollinator attractants, most act as defensive toxins and herbivore deterrents. See supplementary Figure S1 for general structure of each group of terpenes.

\subsubsection{Monoterpenes}

Monoterpenes, a major group of terpenes, are associated with the 10-carbon-containing isoprenoids and are extensively used in health care products and cuisine. Natural monoterpenes and their derivatives have critical pharmaceutical properties such as antioxidant, 
anticancer, antibacterial, antifungal, antiviral, antiaggregating, anti-inflammatory, antihistaminic antispasmodic, and local anesthetic activities [24]. Monoterpene derivatives (e.g., $\beta$-pinene, $\alpha$-pinene, myrcene, and limonene) are toxic to insects; they accumulate in the resin ducts in twigs, needles, and trunks. They are also potentially involved in growth regulation and heat tolerance. In the environment, monoterpenes give a specific identity to their respective plants. Examples include citral, which is a monoterpene present in lemons that gives them their special smell, and thymol, which forms part of the flavor of mandarin oranges. Some monoterpenes are present in the scent of flowers and can attract plant pollinators, whereas others are repellents of predators [25].

\subsubsection{Sesquiterpenes}

Sesquiterpenes, another major class of terpenes, contain three units of isoprene and are found in cyclic and acyclic forms. They occur in oxygenated forms or in the form of hydrocarbons such as alcohols, lactones, aldehydes, and ketones. More than 5000 sesquiterpene compounds have been identified in the plant kingdom, most commonly in Asteraceae [26] like $\alpha$-bisabolene and $\beta$-caryophyllen. Sesquiterpenes (like costunolides) are characterized by a five-membered lactone ring. They are known for their defensive action against herbivores and ability to repel the feeding of mammals and insects [27]. Sesquiterpenes also have a regulatory role in the initiation and preservation of bud and seed dormancy and can act as transcriptional activators [28].

\subsubsection{Diterpenes}

Diterpenes, which are composed of two terpene units, are biosynthesized by plants, animals, and fungi through the isoprenoid pathway (i.e., the mevalonate pathway) using geranylgeranyl pyrophosphate. Depending on their core skeleton, they can be divided into linear, bicyclic, tricyclic, tetracyclic, penta, and macrocyclic forms. Diterpenes are the precursors of biologically essential metabolites such as retinal, retinol, and phytol, which have anti-inflammatory and antimicrobial activities. They show significant biological activity in various medicinal plants; for example, ingenol-3-angelate and paclitaxel are effective against cancer. Other diterpenes, such as forskolin, salvinorin A, triptolide, carnosic acid, and ginkgolide B, are potentially involved in analgesic, cardioprotective, antioxidant, and anti-inflammatory activities [29]. Gibberellins (phytohormones) are important diterpenes that have a key function in seed germination, flower and fruit setting, leaf expansion, biomass production, stomatal conductance, and $\mathrm{CO}_{2}$ fixation [15].

\subsubsection{Triterpenes}

Triterpenes, a group of terpenes consisting of six isoprene units, have been identified in more than 200 skeletons, with about 20,000 different terpenes reported to date [30]. Triterpenes contain 30 carbons and can be found in linear, dicyclic, tricyclic, tetracyclic, and pentacyclic forms that are mainly derived from squalene [31]. The prominent members of this group show antiviral, antibacterial, antifungal, antioxidant, anticancer, and antiinflammatory activities [32]. They play important roles in pest and pathogen control, as well as food quality in crop plants, and are also contained in pharmaceutical, food, and cosmetics products [33].

\subsubsection{Polyterpenes}

Polyterpenes, such as tetraterpenes, have high molecular weights, as they comprise several hundred isoprene units. Rubber is a polyterpene polymer consisting of many repeating isoprene units. Usually, rubber is present in laticifers, in which it provides protection against herbivores and enables wound healing as a defense mechanism [34]. Polyterpenes act as viscosity diluents like waxes as well as act as a co-tackifiers [35]. 


\subsection{Sulfur-Containing SMs}

Sulfur-containing secondary metabolites are a relatively minor group of plant SMs including about 200 compounds. The group encompass the well-known glucosinolates and their breakdown products such as thiocyanates, isothiocyanates, epithionitriles, and oxazolidinethiones [36]. Sulfur-containing SMs are essential for protein synthesis: with a lack of sulfur, protein synthesis is reduced. The symptoms of sulfur deficiency are similar to those of nitrogen deficiency, but are only seen in the young leaves of plants [37]. Sulfur-containing SMs have a significant effect on plant health because plants cannot utilize nitrogen properly without having sufficient sulfur [38]. Studies have reported that sulfur- and nitrogen-containing SMs are affected by sulfur and nitrogen supply, i.e., the ideal amount of each respectively enhances the ability of the plant to deal with various environmental stresses. Sulfur-containing SMs include glutathione, glycosphingolipid, phytoalexins, allinin, thionins, and defensins, which are directly or indirectly linked to the plant defense system [15].

\subsection{Nitrogen-Containing SMs}

Many plant SMs contain nitrogen in their skeleton. Nitrogen-containing SMs are synthesized from common amino acids and can be divided into main four categories: alkaloids, cyanogenic glycosides, glucosinolates, and nonprotein amino acids. SMs occurrence in plant species and their biological activities are presented in Table 1.

Table 1. The occurrence and biological activities of secondary metabolites (SMs) in various plant species.

\begin{tabular}{|c|c|c|c|c|}
\hline SM Name & Class & Plant & Biological Activity & References \\
\hline \multicolumn{5}{|c|}{ Terpenes } \\
\hline Iridoids & Monoterpenes & $\begin{array}{c}\text { Eucomis autumnalis/Scrophularia } \\
\text { ningpoensis }\end{array}$ & Drought stress & [39] \\
\hline Cineole & Monoterpenes & Mentha spicate/Thymus vulgaris L. & Drought stress & [40] \\
\hline Tanshinone & Diterpenes & Salvia miltiorrhiza & Hyperosmotic stress & [41] \\
\hline Retinol & Diterpenes & Daucus carota & Oxidative stress & [42] \\
\hline Carnosic acid & Diterpenes & Salvia officinalis $\mathrm{L}$. & Oxidative stress/Drought stress & [43] \\
\hline Phytol & Diterpenes & Solanum lycopersicum & Light stress/Temperature stress & [44] \\
\hline Abietic acid & Diterpenes & Leguminous/Pine trees & Antipathogen & [45] \\
\hline Gikolides & Diterpenes & Ginko biloba & Biotic stress & [46] \\
\hline Menthol & Monoterpenes & $\begin{array}{c}\text { Mentha spicata L./Arabidopsis } \\
\text { thaliana }\end{array}$ & Antifungal & [47] \\
\hline Catalpol & Monoterpenes & Plantago lanceolata & Drought stress & [48] \\
\hline Pyrethroids & Monoterpenes & Chrysanthemum morifolium & Anti-insect & [49] \\
\hline$\alpha$-pinene $/ \beta$-pinene & Monoterpenes & $\begin{array}{l}\text { Chrysanthemum } \\
\text { morifolium/Conifers }\end{array}$ & Antipest/Drought stress & [49] \\
\hline Artemisinin & Sesquiterpene & Artemisia annua $\mathrm{L}$. & $\begin{array}{l}\text { Light stress/Cold } \\
\text { stress/antimalaria }\end{array}$ & [50] \\
\hline Gossypol & Sesquiterpene & Gossypium L. & Antipathogen/Antipest & [51] \\
\hline Limonoids & Triterpenes & Citrus fruits & Antiherbivore & [49] \\
\hline Ginsenosides & Triterpenes & Panax quinquefolius & Light stress & [52] \\
\hline Sterols & Triterpenes & Asclepias syriaca & Antiherbivore/Anti-insect & [53] \\
\hline \multicolumn{5}{|c|}{ Phenolic Compounds } \\
\hline $\begin{array}{l}\text { Cyanidin/Peonidin/Malvidin/ } \\
\text { Pelargonidin/Delphinidin }\end{array}$ & Flavonoids & Cabbage/Radish/Lettuces & Abiotic stresses & [54] \\
\hline Tangeretin/Nobiletin & Flavonoids & Citrus & Abiotic stresses & [55] \\
\hline Leteolin/Chrysoeriol/Apigenin & Flavonoids & Apium graveolens/Thymus vulgaris & Biotic/Abiotic stresses & [55] \\
\hline Quercetin/Qaempferol/Myrecetin & Flavonoids & $\begin{array}{c}\text { Allium cepa/Allium } \\
\text { porrum/Brassica oleracea var. }\end{array}$ & Oxidative stress/Antipathogen & [56] \\
\hline
\end{tabular}


Table 1. Cont.

\begin{tabular}{|c|c|c|c|c|}
\hline SM Name & Class & Plant & Biological Activity & References \\
\hline Genistein/Daidzein/Glycitein & Flavonoids & Glycine max & Oxidative stress & [57] \\
\hline Podophyllin/Urushiol & Lignans & Podophyllum & Biotic/Abiotic stress & [58] \\
\hline Pinoresinol & Lignins & All land plants & Cold stress & [59] \\
\hline Oleuropein & Polyphenolic & Olea europaea & Salt stress & [60] \\
\hline Gallic acid & Phenolic & Pisum sativum & Antifungal & [56] \\
\hline Ferulicacid & Phenolic & Oryza sativa & Antifungal & [61] \\
\hline Gallotannin & Tannin & $\begin{array}{l}\text { Quercus robur/Tsuga/Lotus } \\
\text { corniculatus/Legumes }\end{array}$ & Oxidative stress/Antibacterial & {$[62]$} \\
\hline Tannic acid & Tannin & Gossypium & Salt stress/Oxidative stress & [63] \\
\hline $\begin{array}{l}\text { Umbelliferone/Esculetin/ } \\
\text { Scopoletin }\end{array}$ & Coumarins & $\begin{array}{l}\text { Olea europaea/Avena sativa } \\
\text { Apiaceae/Asteraceae/Fabaceae }\end{array}$ & Biotic/Abiotic stress & [64] \\
\hline Psoralin & Furanocoumarins & Psoralea corylifolia $L$ & Biotic stress & [65] \\
\hline Bergaptene & Furanocoumarins & Ammi majus & Antibacterial & [66] \\
\hline Gallic/Salicylic acids & Phenolic acids & Berries/Nuts & Antiviral & [67] \\
\hline Juglone & Napthoquinones & Juglans regia & $\begin{array}{l}\text { Chemical detoxificante/Abiotic } \\
\text { stress/Oxidative stress }\end{array}$ & [68] \\
\hline Plumbagin & Napthoquinones & $\begin{array}{l}\text { Plumbago spp./Drosophyllum } \\
\text { spp. }\end{array}$ & Antimicrobial/Anti-insect & [69] \\
\hline Emodin & Anthraquinones & Higher plants & $\begin{array}{l}\text { Antiherbivore/Antipathogen/ } \\
\text { Light stress }\end{array}$ & [70] \\
\hline Caffeic & Hydroxycinnamic acids & Prosopis farcta & $\begin{array}{l}\text { Heavy metal stress/Drought } \\
\text { stress/Salt stress }\end{array}$ & [71] \\
\hline Ferulic acids & Hydroxycinnamic acids & $\begin{array}{c}\text { Vitis vinifera L./Chrysanthemum } \\
\text { morifolium }\end{array}$ & Drought stress & [72] \\
\hline Bergenin & Isocoumarins & Saxifraga ligulata & Antiviral/Oxidative stress & [73] \\
\hline Eusiderin & Neolignans & Eusideroxylon zwagery & Antifungal & [74] \\
\hline Mangiferin & Xanthones & Mangifera indica & $\begin{array}{l}\text { Oxidative stress/Biotic/ } \\
\text { Abiotic stress }\end{array}$ & [75] \\
\hline Amentoflavone & Biflavonoids & $\begin{array}{c}\text { Selaginellaceae/Cupressaceae/ } \\
\text { Euphorbiaceae }\end{array}$ & $\begin{array}{c}\text { Oxidative } \\
\text { stress/Antiviral/Antifungal }\end{array}$ & [76] \\
\hline Agathisflavone & Biflavonoids & Anacardium occidentale & $\begin{array}{c}\text { Oxidative } \\
\text { stress/Antimicrobial/Antiviral }\end{array}$ & [77] \\
\hline \multicolumn{5}{|c|}{ Sulfur-containing SMs } \\
\hline Defensins/Thionins/Lectins & & Higher plants & Antifungal/Antibacterial & [78] \\
\hline Brassinin & Phytoalexin & Brassica campestris L. & Biotic/Abiotic stress & [79] \\
\hline Wasalexins & Phytoalexin & Wasabia japonica & Biotic/Abiotic stress & [80] \\
\hline Camalexin & Phytoalexin & Camelina sativa & Biotic stress & [79] \\
\hline Glucoraphanin & Glucosinolates & Brassica oleracea & UV-B stress & [81] \\
\hline Neoglucobrassicin & Glucosinolates & Brassica oleracea & UV-B stress & [81] \\
\hline Glucobrassicin & Glucosinolates & Brassica rapa & Wounding Stress & [82] \\
\hline Sinigrin & Glucosinolates & Brassica oleracea & Salt stress & [83] \\
\hline \multicolumn{5}{|c|}{ Nitrogen-containing SMs } \\
\hline Narkotine/Codeine/Morphine & Alkaloid & Papaver somniferum & Drought stress & [84] \\
\hline Monocrotaline & Alkaloid & Crotalaria & Antiherbivore & [85] \\
\hline Tomatidine & Alkaloid & Solanum lycopersicum & Salt stress & [86] \\
\hline Senecionine & Alkaloid & Senecio jacobaea & Antiherbivore & [87] \\
\hline Vincristine/Vinblastine & Alkaloid & Catharanthus roseus & UV-B stress & [88] \\
\hline Pyrrolizidine & Alkaloid & Panax quinquefolius & Antiherbivore & [89] \\
\hline Mimosine & Nonprotein amino acids & Mimosa pudica & Antiherbivore/Antimicrobial & [90] \\
\hline
\end{tabular}


Table 1. Cont.

\begin{tabular}{|c|c|c|c|c|}
\hline SM Name & Class & Plant & Biological Activity & References \\
\hline Citrulline & Nonprotein amino acids & Cucumis melo L. & Drought stress/Salt stress & [91] \\
\hline Pipecolic acid & Nonprotein amino acids & Calliandra & Antiherbivores & [92] \\
\hline $\begin{array}{l}\text { Canavanine/Azetidine-2- } \\
\text { carboxylic acid }\end{array}$ & Nonprotein amino acids & Legumes & Antiherbivore/Antipathogen & [15] \\
\hline Amygdalin & Cyanogenic glucoside & $\begin{array}{l}\text { Almonds/Apricot/ } \\
\text { Cherries/Peaches }\end{array}$ & Antiherbivore & [15] \\
\hline Dhurrin & Cyanogenic glucoside & Sorghum bicolor $\mathrm{L}$. & Drought stress/Antiherbivore & [93] \\
\hline Linamarin/Lotaustralin & Cyanogenic glucoside & Lotus japonicus & Antiherbivore/Drought stress & [94] \\
\hline
\end{tabular}

\section{Responses of SMs to Abiotic Stress}

SM accumulation, which is dependent on plant growth condition and influences related metabolic pathways, is often associated with stress conditions, and may include signal molecules and elicitors. Due to the sessile nature of plants, they are regularly exposed to a wide range of environmental stresses, such as temperature, drought, salinity, alkalinity, UV, pathogens, and herbivores, which can cause serious damage to the plants [95]. Exposure to abiotic stress causes various common reactions that can lead to cellular dehydration, which in turn results in the generation of osmotic pressure and removal of water from the cytoplasm to vacuoles. External factors can adversely affect some process associated with growth and development in plants, and their ability to biosynthesize SMs ultimately leads to variation in their overall phytochemical profiles, which play important roles in the production of bioactive substances $[96,97]$. In other words, plant SMs are regularly synthesized in response to environmental stress; hence, secondary metabolism, in part, determines the ability of plants to adapt and survive in response to environmental stimuli and stress during their lifetime, while also enabling ecological relationships to take place between plants and other organisms. Below, we briefly discuss the synthesis of SMs in association with the major abiotic stresses.

\subsection{Temperature}

Global temperature increased by $\sim 0.47^{\circ} \mathrm{C}$ in the twentieth century. Global warming, it is estimated, will substantially affect the production of plant SMs. This is because high, as well as low, temperatures are harmful abiotic stresses that can impact the survival of plants; therefore, adapted plants alter their metabolism when faced with such temperatures to increase the level of essential metabolites and thereby tolerate unfavorable conditions [98]. High temperatures enhance the biosynthesis of alkaloids; in contrast, alkaloid synthesis (e.g., morphinane, phthalisoquinoline, and benzylisoquinoline) is inhibited at low temperature in plants such as Papaver somniferum. For example, the alkaloid hydroxycamptothecin is involved in heat-shock tolerance; hydroxycamptothecin accumulation was reported to increase 6-fold in the leaves of Camptotheca acuminata seedlings during incubation at $40{ }^{\circ} \mathrm{C}$ for $2 \mathrm{~h}$ [99]. Various cultivars of Lupinus angustifolius exposed to high temperature in the field also significantly induce alkaloid accumulation [100]. Conversely, Catharanthus roseus leaves show reduced levels of vindoline and catharanthine when exposed to low temperatures [101]. Temperature is also correlated with terpenoids in coniferous and deciduous plants: emission of isoprenes from Quercus rubra and Quercus alba at high temperatures was double that recorded at low temperatures [102]. In response to high temperature, terpenes accumulate at high concentrations in Daucus carota with the exception of $\alpha$-terpinolene, which decreases with increasing temperature. In the leaves of Zea mays seedlings, anthocyanin accumulation is enhanced with the duration and severity of low temperature. In Rhodiola rosea, temperature alters SM synthesis and induces SM accumulation in combination with heavy metal stress [103]. Phenylamides have reactive oxygen species (ROS) scavenging properties during stress conditions; they are produced in tobacco and beans when the plants are exposed to heat shock and water stress [104]. Low temperature en- 
hances the synthesis of phenolic compounds and their subsequent integration in the plant cell wall as lignin or suberin, while plants adapted to cold environments are associated with the synthesis of chlorogenic acid at high levels [59]. Similarly, temperature influences the synthesis of ginsenosides in the root hairs of Panax ginseng, while Melastoma malabathricum synthesizes high levels of anthocyanin at low temperatures [105].

\subsection{Salinity}

Salinity is a major abiotic stress that leads to cellular dehydration; this causes ionic or osmotic pressure that increases or decreases the accumulation of specific SMs in plants. Salt stress may act as an elicitor of SMs for the protection of cells from the oxidative damage caused by ion accumulation at the cellular and subcellular levels; thus, SMs reduce the toxic effect of salinity [106]. Plant genotypic flexibility in diverse saline environments, both in vitro and in vivo, enables plants to synthesize SMs that are crucial for their survival in such conditions. Indeed, salinity has physiological, biochemical, morphological, and biosynthesis effects on plant SM profiles due to the induction of stress and defense response pathways involved in ROS generation and responsible for the modulation of SMs [107]. When salt stress occurs, the ability of roots to absorb sufficient water reduces, which may in turn lead to water scarcity and osmotic pressure caused by high accumulation of salt [108]. As a result of osmotic pressure, membrane functional stability, nutrient balance, and redox homeostasis are disturbed, which in turn affects the primary metabolites that are the precursors of SMs [109]. In recent decades, the physiological and molecular effects of salt stress on the production of important SMs in crop species have been reported. These SMs include terpenoids, flavonoids, alkaloids, steroids, and phenolics which function in plant defensive responses to salt stress and protect plant growth physiology [110]. For instance, anthocyanins were reported in higher concentrations during salt stress, while anthocyanin levels were reduced during salt stress in salt-susceptible species [111]. Salt-tolerant alfalfa increase their proline levels under salt stress, and a similar trend was found in Lycopersicon esculentum and Aegiceras corniculatum. Although polyphenols are generally associated with abiotic stress, polyphenol accumulation also increases in plant tissues under salt stress in various plants [112]. Furthermore, phenolic compounds increase in pepper plants under salt stress, which is consistent with the response of polyamines that are involved in the saltstress response [113]. In addition, Sesuvium portulacastrum under salt stress reduces certain physiological process due to the synthesis of SMs: the strong antioxidant properties of these SMs play an important role in the plant's survival under saline stress [114]. Halophytes, which grows in saline soil and spend an extensive part of their life under salt stress, have high osmotic pressure that enables them to uptake sufficient water and synthesize SMs via various mechanisms [109].

\subsection{Water (Drought and Flooding)}

Drought, a prevalent and multidimensional abiotic stress in the plant kingdom, occurs widely in arid and semiarid areas throughout the world. Drought stress usually leads to morphological, physiological, biochemical, ecological, and molecular changes in plants; hence, it can adversely affect the quality and quantity of plant biomass [115]. During their evolution, plants have adapted to drought conditions by accumulating SMs, such as terpenes, alkaloids, and phenolic complexes, via ionic or osmotic stress induction; however, increased SM accumulation is usually accompanied by reduced biomass [116]. For instance, the concentrations of phenolic compounds in Hypericum brasilience and Pisum sativum increase when they are exposed to drought stress [117]. Phenolic compounds typically accumulate during drought stress because of changes in the phenylpropanoid pathway: most of the key genes of this pathway are stimulated by drought stress. For example, drought stress induces activation of the PAL gene in lettuce plants and expression of several genes related to flavonoid biosynthesis in Scutellaria baicalensis [118]. Similarly, accumulation of terpenes in Salvia officinalis increases during drought stress while accumulation of biomass is reduced [119]. Drought stress promotes oxidative stress, which in turn 
enhances flavonoid biosynthesis; flavonoids act as antioxidants and protect plants from the effects of water scarcity. For example, kaempferol and quercetin levels increase in tomato plants under drought stress; these compounds can potentially detoxify the $\mathrm{H}_{2} \mathrm{O}_{2}$ molecules produced during drought stress. Some SMs are reduced, however, during water scarcity, e.g., saponins in Chenopodium quinoa [120]. Researchers can induce and test drought stress in correlation with SMS accumulation in vitro; culture medium (containing nutrients, carbon sources, and osmotic stabilizers) can be manipulated to produce drought conditions with associated effects on the metabolic processes that lead to SM accumulation [121]. For example, manipulation of culture medium significantly impacts accumulation of camptothecin in Nothapodytes nimmoniana and Ophiorrhiza mungos, phenolic compounds in Bellis perennis, and tropane alkaloids in Brugmansia candida [122,123]. The effects of drought on SMs in conifers have also been studied; total terpenes in the seedlings of Pinus sylvestris and Pinus abies were found to be about $32-39 \%$ and $35-45 \%$ higher in drought-affected plants than in control plants, respectively [124].

\subsection{Radiation (Light, $U V$, and Ionization Radiation)}

Light quality can also influence synthesis of bioactive compounds and SMs in plants. The basic components of light include photoperiod (length), power (sum), and quality (repeat/recurrence) [125,126]. Different plant species shows variations in their responses to quantity and intensity of light [127]. Because of the depletion of the ozone layer, concerns have arisen about the effects of UV radiation (UV-B: $280-320 \mathrm{~nm}$ ), which has strong effects on the composition and concentration of plant SMs [127] including alkaloids [128], terpenoids, flavonoids [129], cyanogenic glycosides, tannins, and anthocyanins [130]. Plants are able to adapt to changes in light radiation by accumulating and releasing various SMs, such as phenolic compounds, triterpenoids, and flavonoids, many of which have high economic value and utilization due to their antioxidant properties $[131,132]$. Studies have shown that the duration of light radiation affects the regulation of levels of various phenolic phenylpropane derivatives in the Xanthium species. In comparison with a long period of light exposure, a short period of light exposure reduces caffeoylquinic acids by about $40 \%$ and approximately doubles the reduction in flavonoid aglycone content [133]. Similarly, in Pinus contorta, the concentration of anthocyanins was found to be lower when the plant was grown under short sunlight conditions compared with long sunlight conditions, whereas concentrations of proanthocyanins and flavan-3-ols concentrations were barely altered with variation in sunlight period [134]. In Ipomoea batatas, a significant increase in phenolic acids (e.g., hydroxybenzoic acids and hydroxycinnamic) and flavonoids (e.g., flavonols, anthocyanins, and catechins) content was observed after a long period of light exposure [135].

The synthesis of SMs is also affected by light quality. The phenolic compounds of Lactuca sativa are more sensitive to monochromatic light than combined light. In one study, increasing the proportion of red light affected antioxidant phenols, while phenolic compounds, including caffeic acid, chicoric acid, chlorogenic acid, and kaempferol, as well as ferulic acids, showed similar behaviors [136]. UV irradiation is a factor that in many cases enhances the synthesis of SMs; therefore, it can be used in cell and callus cultures [137-139]. In one study, production of vindoline and catharanthine from Catharanthus species was increased after UV-B radiation treatment [140]. Similarly, glycosyl flavonoid content was found to be significantly higher following UV irradiation treatment [137]. In addition, Regvar, et al. [141] reported the effect of UV irradiation on the concentration of quercetin catechin and rutin in Fagopyrum tataricum and Fagopyrum esculentum; they detected a significant increase in quercetin concentration in F. esculentum after UV irradiation treatment.

\subsection{Gaseous Toxins}

Air pollutants, such as sulfur dioxide $\left(\mathrm{SO}_{2}\right)$, can enter plant systems through the roots and stomata during photosynthesis and respiration. Different plants shows various 
responses to $\mathrm{SO}_{2}$, which include photosystem damage [142], variation in stomatal density, and changes in carbon fixation efficiency $[143,144]$. Owing to the importance of sulfur in many important pathways, stomatal uptake of $\mathrm{SO}_{2}$ influences the metabolic profile of the plant. Glucosinolates, which are sulfur-containing metabolites, are thought to be important in sulfur storage, which provides a source of sulfur for the plant when sulfur is not present in the environment [145]. $\mathrm{SO}_{2}$-induced fumigation has been shown to change anthocyanin synthesis, although the low abundance of flavon-3-ol transcripts after fumigation with $\mathrm{SO}_{2}$ indicates that anthocyanin is not rapidly degraded [146]. When considering approaches to supplying sulfur to plants, there is an interest in understanding the effects of the sulfurcontaining gas, hydrogen sulfide $\left(\mathrm{H}_{2} \mathrm{~S}\right)$. High dosages of $\mathrm{H}_{2} \mathrm{~S}$ can induce defoliation, leaf lesions, decreased growth rate, and tissue death in some plants [147]. $\mathrm{H}_{2} \mathrm{~S}$ is also a signaling molecule that promotes antioxidant activities in many plants in response to abiotic stresses. One study showed that application of $\mathrm{H}_{2} \mathrm{~S}$ changes the antioxidant potential of some plants [147]. In this study, incremental levels of sodium hydrosulfide (with $\mathrm{H}_{2} \mathrm{~S}$ as a donor) were applied to the Bronco cabbage (Brassica oleracea) to investigate potential physiological and antioxidative changes; lower treatment levels caused an increase in plant content of carotenoids, anthocyanins, flavonols, total phenolics, and sinigrin [147].

\subsection{Heavy Metals}

Heavy metals have become one of the main abiotic stress agents for plants given the influence of agrotechnology, industry, and their high bioaccumulation and toxicity [148]. Substantial data are available on the effects of heavy metals on plant growth and physiology; however, fewer data are available on the effects of heavy metals on SM production. Heavy metal-induced changes in the metabolic activity of plants can affect the production of sugars, photosynthetic pigments, and proteins. These effects occur because of the inhibition of enzymes involved in the production of these natural products [149]. Heavy metals can also change the synthesis of bioactive compounds by altering certain aspects of secondary metabolism [150]. For example, metals such as Fe, Ag, Ni, and Co have been reported to provoke the synthesis of SMs in various plants [151]. Similarly, in a specific study of Brassica juncea, the effective accumulation of metals (e.g., $\mathrm{Fe}, \mathrm{Cr}, \mathrm{Zn}$, and $\mathrm{Mn}$ ) significantly increased the oil content of the plant by up to $35 \%$ [152]. Following treatment with $\mathrm{Cd}^{2+}$ and $\mathrm{Cu}^{2+}$ in other studies, maximum accumulations of SMs such as shikonin [153] and digitalin [154] occur. In addition, the synthesis of betalains in Beta vulgaris also increases with $\mathrm{Cu} 2+$ treatment, while $\mathrm{Cu}^{2+}$ and $\mathrm{Co}^{2+}$ have stimulatory effects on the synthesis of SMs in this species [155]. Furthermore, $\mathrm{Zn}^{2+}$ treatment $(900 \mu \mathrm{M})$ enhances the production of lepidine in cultures of Lepidium sativum; however, $\mathrm{Cu}$ is more effective than $\mathrm{Zn}$ in increasing the product yield [156]. Similarly, in hairy root cultures of B. candida, cadmium chloride $\left(\mathrm{CdCl}_{2}\right)$ or silver nitrate $\left(\mathrm{AgNO}_{3}\right)$ provokes the overproduction of hyoscyamine and scopolamine [157]. Finally, in Taxus sp. cell cultures, the synthesis of taxol increases with lanthanum earth-metal treatment [158].

\subsection{Pesticides and Aerosols}

Despite the many benefits of pesticides, their use can affect nontarget organisms, including humans and plants, and thereby create abiotic stress conditions [159]. Although pesticide residues are controlled in plants to protect human health [160], this process does not reflect the fact that plant secondary metabolism can be controlled by pesticides. An important question therefore arises: can pesticides induce chemical changes in plants that affect human health [160]? Studies suggest that this might be possible at the time of application but is less critical at the time of consumption [160]. Typically, plant parts such as leaves, roots, and fruits are exposed to pesticides; when they enter the plant, however, pesticides reach different plant parts using the vascular system and cell-to-cell movement (depending on the pesticide's chemical and physical properties). Most plants have a specialized system for sequestration and degradation of pesticides [161]. The metabolic biotransformation of pesticides can be split into different phases. For example, the first phase includes epoxi- 
dation, oxidation, hydroxylation, reduction, hydrolysis, O-dealkylation, N-dealkylation, desulfuration, dehydrogenation, and dehalogenation. Most of these chemical changes are mediated by enzymes whereas some arise from photochemical reactions. The second and third phase reactions involve conjugation of the pesticide and its metabolites with other natural constituents such as glutathione, malonic acid, and glucose [162,163].

To date, most pesticide research has focused on the effects of pesticides, their residues and metabolism, and their impact on human health and the environment. However, the effects of pesticides on plant SMs (both targeted and nontargeted) are largely unknown. Most published data relate to the effects of fungicides and herbicides on flavonoid content and some terpenoid metabolism in plants $[164,165]$. Pesticides may also disturb secondary metabolism indirectly by eliminating nontarget plants species that compete for nutrients and light or serve as habitats for herbivores and pathogens [166]. Pesticide-related changes in plant SMs, such as phenols, not only affect ground-surface organisms and ecological functions but also influence the rhizospheric community if pesticides are applied to plants in the field [167]. Furthermore, after a plant's death, pesticide-induced production of plant phenols may affect its availability as a food for soil organisms or slow the decomposition rate of soil organic matter because the phenols can be persevered for weeks to months after death [168].

\section{Response of SMs to Biotic Stress}

Different methods are used for the biological control of phytopathogens, but one of the most important is the use of medicinal plant extracts, which is aimed at eradicating crop diseases caused by bacteria, fungi, and viruses $[169,170]$. Thus, it is important to study the secondary metabolism of plants in this context, i.e., understanding which phytochemical substances are produced by plants and the biological activities of these phytochemicals [171].

\subsection{Biotic Elicitors}

Elicitors can be characterized as stress factor substances that when added to a living system in small amounts induce or improve the biosynthesis of specific compounds associated with the adaption of plants to stressful conditions. Elicitors may be biotic or abiotic (Figure 1). Biotic elicitors are organic substances that typically contain carbohydrates and develop their signal effects at low concentrations [172]. Here, we discuss types of both biotic and abiotic elicitors.

\subsubsection{Polysaccharides}

In medicinal plants, SM production can be triggered using biotic elicitors. In cell suspension cultures of $P$. ginseng, saponin content significantly increases when oligogalacturonic acid is used as an elicitor [173]. In addition, production of the natural naphthoquinone shikonin is induced by the polysaccharide agaropectin in the cells of Lithospermum erythrorhizon [174]. Similarly, plumbagin content in Plumbago rosea is increased via chitosan treatment [69]. Chitin or chitosan also induce the biosynthesis of fluoroquinolone coumarin alkaloids in shoot cultures of Ruta graveolens [175]. Furthermore, using chitosan in cell cultures of Vitis vinifera enhances the production of viniferins and trans-resveratrol [176]. Additionally, production of naphtodianthrone and phenylpropanoid is enhanced by chitin treatment in cell suspension cultures of Hypericum perforatum [177].

\subsubsection{Yeast}

Yeast extract has been used for decades as a biotic elicitor for the production of SMs. In tomato plants, yeast induces the production of ethylene, while in Phaseolus vulgaris it induces bacterial resistance [178]. It also induces tanshinone when used as an elicitor in Perovskia abrotanoides root tissue culture [179]. 


\subsubsection{Fungal Elicitors}

Pathogen-induced biotic elicitors are mainly used to activate plant defense systems (Table S1). For the production of phenylpropanoids/flavonoids in plant cells, the use of fungal pathogenic and nonpathogenic elicitors is one of the most efficient strategies [180]. Botrytis spp. (necrotrophic pathogens) kills host cells via the secretion of toxins before taking host nutrients. In contrast, biotrophic pathogens (e.g., Fusarium spp. or Phoma spp.) do not kill the host cells but rather alter the host's metabolic and secretory systems to take nutrients from the host cells [181]. In related studies, the monolignol pathway is stimulated by fungal mycelial extracts in cell cultures of Linum usitatissimum [182]. In soybean and potato plants, microbial resistance can be induced by cultures of Phytophthora. Resistance to Phytophthora has been induced in Capsicum annuum using extracts obtained from microbial-rich composts [183]. The production of catharanthine, serpentine, and indole alkaloids (e.g., ajmalicine) in cell suspensions of $C$. roseus is induced by fungal cell-wall fragments [184]. These fragments also induce the production of raucaffrincine and 12-oxo-phytodienoic acid in Rauwolfia canescens [185]. Moreover, when fungal mycelia are used as elicitors in Dioscorea deltoidea, diosgenin content increases by up to $72 \%$ in the plant's cells [186]. Similarly, a more than eight-fold increase in the production of sanguinarine, morphine, and codeine has been observed in P. somniferum when fungal spores are used for the elicitation [187]. Furthermore, in cultures of R. graveolens, the production of antimicrobial alkaloids (e.g., acridone epoxide) increases by up to 100-fold when fungal polysaccharides are added [188].

\subsubsection{Bacterial Elicitors}

When bacterial elicitors are used in the hairy root culture of Scopolia parviflora, they activate the synthesis of scopolamine by inhibiting $\mathrm{H} 6 \mathrm{H}$ (hyoscyamine $6 \beta$-hydoxylase) expression [46]. In addition, increased production of glycyrrhizic acid has been observed in the roots of Taverniera cuneifolia following treatment with Rhizobium leguminosarum, while significantly increased amounts of glycyrrhizic acid have been noted when Bacillus cereus, Agrobacterium rhizogenes, and Bacillus aminovorans are instead used for the elicitation [189]. In another study, Rhizobacterium induced the production of pseudohypericin and hypericin in the seedlings of H. perforatum [190].

\subsection{Hormonal Elicitors}

In elicitation experiments, various plant hormones have also been tested [191]. Jasmonic acid and salicylic acid and their derivatives have been well studied because of the key roles they play in the response to plant defense (Table S2).

\subsubsection{Jasmonates}

The jasmonates, which comprise methyl jasmonate and jasmonic acid, are a group of compounds containing cyclopentanone that are key factors in the plant defense system. They have been shown to improve the production of SMs in in vitro cultures. For several plant secondary metabolic pathways, jasmonates constitute an essential class of elicitors; typically, they elicit SM biosynthesis when plants face unique environmental stresses [192]. Jasmonic acid is considered a signal molecule of plants following wounding or pathogen attack. In different cell cultures, jasmonic acid and its more active derivative methyl jasmonate can induce the development of a broad range of plant SMs such as rosmarinic acid, terpenoid indole alkaloid, and plumbagin $[193,194]$. For example, rosmarinic acid production in Mentha piperita can be elicited by jasmonic acid [193]. It also affects the production of anthocyanin in $V$. vinifera and production of plumbagin in the hairy roots of Plumbago indica [195]. Methyl jasmonate and jasmonic acid are also used as inducers of stilbene production in V. vinifera foliar cultures [196], V. vinifera cell cuttings [197], and Vitis rotundifolia root hair cutting cultures [198]. Furthermore, the addition of methyl jasmonate to $V$. vinifera in cell cultures encourages the production of anthocyanin compounds [199]. The use methyl jasmonate with transgenic technology also vastly increases the production 
of tanshinone compounds in Salvia miltiorrhiza plant hairy roots [200], as well promoting withanone, and withanolide-A in hair root cultures of Withania somnifera [201]. The production of bacoside $\mathrm{A}$, which is a notable triterpenoid saponin compound that shows nootropic healing activity in in vitro stem cultures of Bacopa monnieri, can also be increased by methyl jasmonate [202]. Furthermore, methyl jasmonate increases the production rate of andrographolide compounds in cell cultures of Andrographis paniculate [203], and increases production of soyasaponin in Glycyrrhiza glabra [204]. Finally, methyl jasmonate has been shown to increase the manufacturing output of paclitaxel in Taxus cuspidate and Taxus canadensis [205], and to enhance production of the raspberry ketone benzalacetone in the seedlings of Rubus idaeus [206].

\subsubsection{Salicylic Acid}

The formation of SMs in plants may also be induced by salicylic acid, which is well known for the systemic acquired resistance to several pathogens that it induces in plants. For example, salicylic acid can significantly enhance the development of tanshinone in S. miltiorrhiza hairy roots via transgenic technology [200]. Furthermore, in salicylic acidprovoked hairy root cultures of $W$. somnifera, the production of compounds with anolide A, withaferin A, and withanone was observed to have increased by [201]. In cell suspension cultures of $V$. vinifera, salicylic acid was able to enhance the production of stilbene [207]. It also triggers the production of alkaloids including vinblastine and vincristine in periwinkle plants [208], the tropane alkaloid scopolamine in Brugmansia candida plant hairy root cultures, and pilocarpine compounds in jaborandi plant leaves [209]. After treatment with salicylic acid, Rubia cordifolia shows enhanced production of anthraquinone [210]. Terpenoid base secondary metabolism can also be affected by salicylic acid treatment, and it initiates the accumulation of triterpenoid ginsenoside compounds in ginseng plants as well as production of glycyrrhizin in licorice plants [211,212]. Finally, monoterpene production is known to be enhanced by salicylic acid given suitable conditions [213].

\subsubsection{Gibberellic Acid}

The phytohormone gibberellin is also an active enhancer of SM production [214]. The diterpenoid compound gibberellic acid is synthesized in the same pathway used for artemisinin biosynthesis $[215,216]$. Various studies have investigated the use of gibberellic acid as an elicitor. For example, it was used to enhance the production of caffeic acid derivatives and tanshinones in hairy root cultures of Echinacea pupurea and S. miltiorrhiza [217,218]. Gibberellic acid has also been used in Artemisia annua to boost amounts of artemisinin [219]: it was used as an elicitor to enhance the biosynthesis of polyphenolics (flavonoids and phenolics) in suspended Artemisia cells.

\section{Transcription Factors and Genes Associated with SMs}

The inducible synthesis of SMs and the transcription of associated biosynthetic genes are strongly altered at various levels through transcriptional regulation via TFs. TFs are actually DNA binding proteins that attach to the promoter regions of target genes and alter the rate of transcriptional initiation via RNA polymerases. To regulate expression of enzyme genes, TFs can integrate internal and external signals and thereby monitor the accumulation of SMs. Regulation of genes associated with the SM biosynthesis pathway is under the influence of many TFs at various levels [220]. The identification of TFs and research on their regulatory mechanism in the SM biosynthesis pathway has increased in recent decades. In this section, we provide a review of the TFs associated with regulation of the SM pathway in various plant species (Figure 1).

\subsection{WRKY TFS}

The WRKY TFs family has been widely studied in plants under stress conditions. The inducible expression pattern of WRKY genes supports their participation in the modulation of defense-related SM biosynthesis. Members of the WRKY family have a 60-amino-acid 
conserved domain that is responsible for gene regulation and overcoming the interaction with W-boxes of the target promoters. Plant WRKY TFs are largely involved in stress responses; they can be regulated by wound or jasmonic acid signaling, and they alter the expression of genes involved in the biosynthesis of various SMs such as alkaloids, terpenoids, and their subclasses [221]. For example, in tobacco plants, WRKY3 and WRKY6 are associated with the biosynthesis of volatile terpenes [222]. In cotton plants, WRKY1 regulates gossypol biosynthesis by binding to the promoter region of the gene involved in cadinene synthesis. In Artemisia annua, WRKY1 regulates artemisinin biosynthesis by binding to the promoter of the sesquiterpene synthesis gene [223]. WRKY1 was also studied in potato plants infected with late blight, in which it attached to the promoter site of the gene involved in hydroxycinnamic acid amide (HCAA) biosynthesis via modulation of the phenylpropanoid pathway [224]. The genes associated with HCAA, namely ACT, DGK, and GL1, are activated by the TF TaWRKY70 when a fungal biomass is encountered on wheat [225]. Similarly, HvWRKY23 promotes the expression of the genes PAL, CHS, and $H C T$, which are responsible for the induction of HCAA biosynthesis during Fusarium head blight infection [226]. In V. vinifera, VviWRKY24 enhances the expression of the VviSTS29 gene, which is responsible for biosynthesis of resveratrol, which in turn confers antimicrobial resistance [227]. Furthermore, SsWRKY18, SsWRKY40, and SsMYC2 are responsible for regulation of abietane-type diterpene accumulation in Salvia sclarea; these compounds have antibacterial and antifungal properties [228]. It has been reported that silencing WsWRKY1 in W. somnifera significantly decreases the accumulation of phytosterol, which in turn decreases tolerance to bacteria, fungi, and insects [229]. In potato plants, StWRKY8 enhances the expression of the genes TyDC, NCS, and COR2, which are involved in the biosynthetic pathway responsible for benzylisoquinoline alkaloid production (these are antimicrobial agents) [230]. In addition, ZmWRKY79 increases the accumulation of phytoalexins in maize under stress conditions [231]. Furthermore, the expression of $d b a t$ in Taxus chinenesis, which is promoted by the TF TcWRKY1, results in increased accumulation of taxol [232]. In C. roseus, CrWRKY1 is induced by jasmonic acid to play a significant role in the biosynthesis of terpenoid indole alkaloids. CrWRKY1 also promotes the TDC, which is a gene involved in the biosynthesis pathway of terpenoid indole alkaloids [233]. Finally, a WRKY TF in Panax quinquefolius, namely PqWRKY1, enhances accumulation of triterpene ginsenoside (41). Thus, a single TF is not necessarily responsible for the concerted transcriptional activation of the whole biosynthesis pathway.

\subsection{MYB TFS}

Among the various TFs, MYBs are involved in the biosynthesis of SMs and participate in various biological processes in plants such as growth, reproduction, and stress responses. MYB TFs are characterized by different numbers of DNA-binding domains consisting of 50-53 amino acids of four imperfect repeats. They can be categorized into four sub classes, i.e., R1, R2, R3, and R4, depending on DNA-binding domain repeats. The R2R3 family of MYB TFs is significantly associated with the regulation of various SM pathways in different plant species. For instance, AtMYB113, AtMYB114, AtMYB75, and AtMYB90 in Arabidopsis thaliana are potentially involved in the regulation of anthocyanin residues via alteration of the phenylpropanoid pathway [234]. Additionally, MYB TFs may also be involved in the biosynthesis of GLs, flavonoids, HCAAs, and proanthocyanins. Moreover, in Arabidopsis, MYB29 and AtMYB76 are associated with the accumulation of aliphatic glucosinolate in aerial parts, whereas AtMYB34, AtMYB51, and AtMYB122 affect indole glucosinolate accumulation by altering the expression of tryptophan biosynthesis genes such as CYP79B2, CYP79B3, and CYP83B1 [235]. Another study reported that the triple mutant of MYB-34, MYB-51, and MYB122 in Arabidopsis shows a considerable reduction in indole glucosinolate accumulation, which in turn increases susceptibility to Plectosphaerella cucumerina [236]. CsMYBF1 in citrus plants activates the expression of CHS, which is a gene involved in the biosynthesis of certain flavonoids [237]. Similarly, SbMYB8 from Scutellaria baicalensis plants enhances the expression of $\mathrm{CHS}$ in transgenic tobacco, which in 
turn increases the regulation of flavonoids and enhances tolerance to drought stress [238]. A recent study showed that CsMYB2/CsMYB26 from Camellia sinensis plants binds to the promoter region of the genes $\mathrm{CsF}^{\prime} \mathrm{H}$ and $\mathrm{CsLAR}$ and thereby enhances the accumulation of flavonoids, which are responsible for tolerance against blister blight disease caused by Exobasidium vexans [239]. In tobacco plants, MYB-JS1 is involved in the regulation of the phenylpropanoid pathway, whereas MYB6 and MYB12 in Asiatic hybrid lily plants are involved in the biosynthesis of anthocyanin [240]. Researchers have also reported that AtMYB11, AtMYB12, and AtMYB111 in Arabidopsis are significantly involved in the regulation of flavonoid biosynthesis, while heterologous expression of AtMYB TFs in various plants is also responsible for flavonoid accumulation [241]. Aside from the positive roles of AtMYBs in plant process, AtMYB75 negative affects flavonoid synthesis and significantly reduces the accumulation of kaempferol-3,7-dirhamnoside, which increases the susceptibility of plants to insect attack [242]. In contrast, MYB30, MYB55, and MYB110 in rice plants activate phenylpropanoid pathway genes, including $H C T, 4 C L 3, C 4 H$, and $P A L$, which are responsible for the positive accumulation of HCCAs [243]. In poplar trees, PtMYB115 binds to the promoter region of the genes ANR1 and LAR3 to enhance their expression; this results in higher accumulation of proanthocyanin and increased resistance against Dothiorella gregaria [244].

\section{3. bHLH TFS}

The bHLH TFs are potential regulators of stress response mechanisms and usually interact with MYB proteins to generate complexes that enhance the expression of specific genes. These TFs are 60-amino-acid proteins with bipartite conserved domains; the key residue at the N-terminal allows the binding of bHLH to DNA, while two alpha helices facilitate the association of helix-loop-helix with proteins to form a homo/heterodimeric complex. As important modulators of stress responses, the bHLH TFs regulate the biosynthesis of SMs such as anthocyanin, alkaloids, glucosinolate, diterpenoid phytoalexin, and saponins. Specifically, bHLH04, bHLH05, and bHLH06 interact with MYB51 to significantly regulate the biosynthesis of GLs in Arabidopsis plants [245]. In the biosynthesis of anthocyanin and flavonoids, bHLHs are widely involved in the regulation of the phenylpropanoid pathway. For instance, the bHLH proteins (e.g., GL3, eGL3, and TT8) bind with MYB in the presence of TTG1, thereby generating a complex of transcriptional regulation that is responsible for the regulation of anthocyanin biosynthesis genes [235]. In addition, MYC2, which is a key regulator of jasmonic acid signaling, belongs to the bHLH protein family and is involved in the regulation of SMs directly or indirectly. Ref. [246] showed that CrMYC2 is also a bHLH family protein; it attaches to the jasmonic acid-responsive element in the ORCA-3 promoter and enhances gene expression, which resultants in altered expression of the genes associated with alkaloid biosynthesis.

In apple plants, MdMYC2 can induce gene expression following jasmonic acid application; consequently, anthocyanin production is enhanced in a transgenic line. MdMYC2 is also known to persistently upregulate anthocyanin-related genes such as DFR, F3H, UF3GT, and CHS. It integrates gibberellic acid and jasmonic acid signaling pathways via an interaction with DELLA protein, leading to upregulation of sesquiterpene genes in Arabidopsis flowers. Occasionally, SMs are regulated by a complex of different TF family proteins such as the MYB-bHLH-WDR complex, which enhances anthocyanin and proanthocyanin regulation in Arabidopsis plants [247]. In rice plants, DPF has been identified as a bHLH TF that regulates the accumulation of diterpenoid phytoalexin via activation of diterpenoid phytoalexin-related genes [248]. In another study, NbbHLH1, NbbHLH2, and NbbHLH3 were associated with nicotine biosynthesis (according to expressed sequence tag screening) via virus-induced gene silencing; of these TFs, NbbHLH1 and NbbHLH2 produce positive regulation by binding to G-box elements in the putrescine N-methyltransferase promoter, whereas NbbHLH3 is a negative regulator [249]. Finally, TSAR1 and TSAR2 are bHLH TFs responsible for the regulation of saponin via activation of the gene HMGR in Medicago truncatula [250]. In short, bHLH TFs act independently or via interaction with other protein 
families to enhance the biosynthesis of various biotic or abiotic stress-inhibiting SMs in various plants.

\section{4. bZIP TFs}

The bZIP TFs are dimeric, transcriptional enhancer proteins, with a conserved leucine zipper and positively charged DNA binding site. They typically function in the modulation of plant biological processes. Members of the bZIP TF family are associated with stress responses, largely with tolerance to ROS and osmotic imbalance. Various Yap-like bZIPs (Yap being a subset of the yeast bZIP protein), such as NapA, AtfA, Aoyap1, Afyap1, and Apyap1, have been found to function in Aspergillus species in response to osmotic, oxidative, nutrient, and drug stresses. Studies have shown that bZIP and oxidative stress regulate biosynthesis of SMs in fungi [251]. RsmA is a bZIP-like protein that suppresses the accumulation of SMs in a mutant line; in contrast, in an overexpressor line, RsamA is an active participant in restoration of SMs [252]. Specific bZIP proteins, including SmbZIP20, SmbZIP7, and AabZIP1, are also known to regulate pharmaceutically important SMs, namely, tanshinone and artemisinin, in Salvia miltiorrhiza and Artemisia annua, respectively [253]. In addition, the light responsive bZIP protein, HY5, is involved in the synthesis of anthocyanin under stress conditions, e.g., MdHY5 in apple plants either interacts with MdMYB10 or acts independently as an anthocyanin regulator [254]. Similarly, in tomato plants, when S1HY5 is attached to the G-box and ACGT region in the promoter site of CHS and DFR, it alters anthocyanin accumulation. It also modulates the expression of QH6 by binding to its binding site and enhancing the biosynthesis of monoterpenes [255]. Terpenoid phytoalexins, which are blast pathogen-resistant elements in rice, are also associated with bZIP proteins. For example, OsTGAP1 is a bZIP protein in rice that binds to the promoter site of the genes OsKSL4 and OsCPS4 and enhances biosynthesis of terpenoid phytoalexins. Additionally, OsTGAP1 moderates the expression of other genes related to terpenoid biosynthesis by modulating the MEP pathway [256]. In contrast to OsTGAP1, OsbZIP79 negatively regulates terpenoid phytoalexins by downregulating MEP pathway genes. Finally, the bZIP-like proteins AtfB and Apyap1 have been shown to enhance the regulation of aflatoxin in Aspergillus parasiticus [257].

\subsection{AP2/ERF TFS}

AP2 /ERF TFs contain a 60 -amino-acid AP2 DNA binding domain; this conserved domain was first described in A. thaliana in the floral homeotic gene APETALA2 (AP2). The $\mathrm{AP} 2 /$ ERF protein can be categorized into four subfamilies on the basis of variation in the additional conserved domain: AP2, ERF, RAV, and DREB (AP2 contains two AP2 domain, ERF contains one AP2 and a B-subfamily, RAV contains one AP2 and a B3 domain, and DREB contains one AP2 and an A-subfamily) [258]. AP2/ERF TFs are broadly involved in mediating plant stress responses via regulation of plant SMs [259]. ORCA and ORCA2 are $\mathrm{AP} 2 / \mathrm{ERF}$ proteins that bind to the promoter sites of genes responsible for the biosynthesis of terpenoid indole alkaloids. Similarly, ORCA3 is a jasmonic acid-inducible AP2/ERF protein that attaches to the JERE element in the promoter site of two genes responsible for the biosynthesis of strictosidine synthase and tryptophan decarboxylase. Furthermore, AaERF1 and AaERF2 are two jasmonic acid-responsive AP2/ERF TFs found in A. annus that attached to the CBF2 and $R A A$ binding site of genes encoding CYP71AV1 and ADS; these TFs activate both the genes and thereby enhance the biosynthesis of artemisinin and artemisinic acids [260]. Jasmonic acid-responsive AP2/ERF TFs have also been isolated from tobacco, which synthesizes several nicotine alkaloids. For example, NtORC1/ERF221 and NtJAP1/ERF10 are AP2/ERF TFs found in tobacco that are positively involved in the transcriptional regulation of the gene $P M T$, which is associated with the nicotine biosynthesis pathway; overexpression of this genes significantly enhances nicotine and pyridine alkaloids [261]. The jasmonic acid-responsive elicitation of nicotine biosynthesis in tobacco also involves the action of AP2/ERF and bHLH proteins, suggesting that combined interaction of TFs is also capable of contributing to SM synthesis [262]. Furthermore, 
the AP2/ERF protein has been shown to bind with CrPRX1 and play a crucial role in vinblastine biosynthesis. However, a lack of additional research has led to predictions that currently unidentified AP2/ERF TFs may be responsible for the regulation of bisindole alkaloids. GAME9, an important TF that also belongs to the AP2/ERF family, is responsible for increasing the biosynthesis of steroidal glycoalkaloids that offer protection against pathogens and insects. Specifically, GAME9 attaches to the binding site of steroidal glycoalkaloid-related genes, e.g., HMGR, C5-SD, CAS, SGTs, and GAMEs, and positively regulates these genes [263]. Some AP2/ERF TFs are also involved in the biosynthesis of phytoprotectants such as saponins. For instance, PnERF1 is a member of the Ap2/ERF family that binds to the promoter site of HMGR, EPS, DS, and SS genes to enhance the biosynthesis of saponins [264]. In addition, the Ap2/ERF GBERF1 regulates the expression of PAL, C4H, C3H, CCR, HCT, CoMT, and F5H genes to enhance the biosynthesis of lignin and protect against Verticilium dahliae [265]. Overall, the AP2/ERF TF family has been studied in detail because of its importance role in mitigating the effects of plant stress.

\subsection{NAC TFS}

NAC TFs constitute a large group of proteins that control various processes in plants including biotic and abiotic stress responses [266]. This family contains more than 100 members in rice and Arabidopsis. NAC proteins are characterized by a NAC domain (with a highly conserved N-terminus) that functions as a binding site; however, the Cterminus is a diverse domain that functions as a transcriptional regulator [266]. Members of this family are involved in the biosynthesis of SMs in response to stress. For instance, the NAC family member ANAC042 binds to the promoter site of camalexin biosynthetic genes, including CYP71A12, CYP71A13, and CYP71B15, to regulate camalexin and increase plant tolerance to Alternaria brassicicola infection [267]. Similarly, PtrNAC72 regulates the expression of the arginine decarboxylase gene $(A D C)$, which is responsible for the biosynthesis of putrescine and can mediate ROS homeostasis in Poncirus trifoliate [268]. Furthermore, MfNAC from Medicago falcate has been reported to regulate glutathione (an antioxidant that can mediate ROS homeostasis) biosynthesis by controlling the expression of the glyoxalase-1 gene (GLO1) [269]. The NAC TF member HbNAC1 is found in Hevea brasiliensis; it binds to the CACG motif in the promoter region of small rubber particle protein, which is involved in the biosynthesis of latex [270]. Furthermore, PaNAC03 is a NAC TF that negatively regulates some genes in the flavonoid pathway, such as CHS, $F 3^{\prime} H$, and $L A R 3$, and thereby enhances plant tolerance against Heterobasidion annosum. Similarly, ANACO3 downregulates DFR, ANS, and LODX genes, which are responsible for the biosynthesis of anthocyanin [271].

\section{Conclusions}

Being sessile in nature, plants develop various indigenous defensive mechanisms to cope with certain environmental stresses. SMs are natural tools used by plants to combat biotic and abiotic stresses. This review encloses an overview of the role of secondary metabolites in response to biotic and abiotic responses via regulation of transcriptional factors and genes involved in environmental stress tolerance. Typically, SMs are produced at low levels in plants; however, their biosynthesis induces with environmental stimuli to increase tolerance against stress condition. This review indicates that, some special SMs, genes and TFs regulates in specific biotic and a biotic stress. Many SMs directly inhibit pest and pathogen infection, some are herbivore deterrents, while most participate in maintaining redox balance by ROS scavenging (which also confers stress tolerance in plants). Some of the major TFs discussed in this review are closely associated with the expression of individual or multiple genes related to the SM biosynthesis pathway. In some cases, a network of two or TFs is required to regulate the associated genes. This review can provide a platform for additional experiments to explore some marker metabolites, genes, and TFs for the development of biotic and abiotic stress tolerant plants. Future research should focus on enhancing bioactive accumulation of SMs in stress conditions. 
Future studies should make use of advanced techniques to test the effects of exogenous application of SMs on the tolerance of plants to biotic and abiotic stress.

Supplementary Materials: The following are available online at https:/ / www.mdpi.com/article / 10.3390 /agronomy11050968/s1, Figure S1. Common structures for each classification of phenolic compounds and terpene. Table S1. Different types of elicitors used to enhance plant secondary metabolites production. Table S2. Hormonal elicitors used to produce specific plant secondary metabolites in plants.

Author Contributions: R.J. and S.A. wrote the manuscript, K.-M.K. conceptualized the study, and M.N. and L.L. reviewed and edited the manuscript. All authors have read and agreed to the published version of the manuscript.

Funding: This work was supported by the National Research Foundation of Korea Grant funded by the Korean Government (NRF-2021M3E5E6022715).

Conflicts of Interest: The authors declare that the research was conducted in the absence of any commercial or financial relationships that could be construed as a potential conflict of interest.

\section{References}

1. Hartmann, T. From waste products to ecochemicals: Fifty years research of plant secondary metabolism. Phytochemistry 2007, 68, 2831-2846. [CrossRef] [PubMed]

2. van Loon, L.C.; Rep, M.; Pieterse, C.M. Significance of inducible defense-related proteins in infected plants. Annu. Rev. Phytopathol. 2006, 44, 135-162. [CrossRef] [PubMed]

3. Akula, R.; Ravishankar, G.A. Influence of abiotic stress signals on secondary metabolites in plants. Plant Signal. Behav. 2011, 6, 1720-1731. [CrossRef] [PubMed]

4. Pradhan, J.; Sahoo, S.; Lalotra, S.; Sarma, R. Positive impact of abiotic stress on medicinal and aromatic plants. Int. J. Plant Sci. 2017, 12, 309-313. [CrossRef]

5. Parker, D.; Beckmann, M.; Zubair, H.; Enot, D.P.; Caracuel-Rios, Z.; Overy, D.P.; Snowdon, S.; Talbot, N.J.; Draper, J. Metabolomic analysis reveals a common pattern of metabolic re-programming during invasion of three host plant species by Magnaporthe grisea. Plant J. 2009, 59, 723-737. [CrossRef]

6. Ahuja, I.; Kissen, R.; Bones, A.M. Phytoalexins in defense against pathogens. Trends Plant Sci. 2012, 17, 73-90. [CrossRef]

7. Jamwal, K.; Bhattacharya, S.; Puri, S. Plant growth regulator mediated consequences of secondary metabolites in medicinal plants. J. Appl. Res. Med. Aromat. Plants 2018, 9, 26-38. [CrossRef]

8. Maeda, H.; Dudareva, N. The shikimate pathway and aromatic amino acid biosynthesis in plants. Annu. Rev. Plant Biol. 2012, 63, 73-105. [CrossRef]

9. Wuyts, N.; De Waele, D.; Swennen, R. Extraction and partial characterization of polyphenol oxidase from banana (Musa acuminata Grande naine) roots. Plant Physiol. Biochem. 2006, 44, 308-314. [CrossRef]

10. Gan, R.Y.; Chan, C.L.; Yang, Q.Q.; Li, H.B.; Zhang, D.; Ge, Y.Y.; Gunaratne, A.; Ge, J.; Corke, H. Bioactive compounds and beneficial functions of sprouted grains. In Sprouted Grains; AACC International Press: St. Paul, MN, USA, 2019; pp. 191-246.

11. Venugopala, K.; Rashmi, V.; Odhav, B. Review on natural Coumarin lead compounds for their pharmacological activity. Biomed. Res. Int. 2013. [CrossRef]

12. Iranshahi, M.; Askari, M.; Sahebkar, A.; Hadjipavlou, L.D. Evaluation of antioxidant, anti-inflammatory and lipoxygenase inhibitory activities of the prenylated coumarin umbelliprenin. DARU J. Pharm. Sci. 2009, 17, 99-103.

13. Evans, W.C. Trease and Evans Pharmacognosy, International Edition E-Book; Elsevier Health Sciences: Nottingham, UK, 2009.

14. Cesarino, I.; Araújo, P.; Domingues Júnior, A.P.; Mazzafera, P. An overview of lignin metabolism and its effect on biomass recalcitrance. Braz. J. Bot. 2012, 35, 303-311. [CrossRef]

15. Mazid, M.; Khan, T.; Mohammad, F. Role of secondary metabolites in defense mechanisms of plants. Biol. Med. $2011,3,232-249$.

16. Gebreyesus, T. Armyworm antifeedants from Clausena anisata (Wild. P Hook, Ex Benth. [Rutaceae]). In Proceedings of the Scientific Working Group on the Use of Naturally Occurring Plant Products in Pest and Disease Control ICIPE, Nairobi, Kenya, 12-15 May 1980.

17. Del Río, J.A.; Díaz, L.; García-Bernal, D.; Blanquer, M.; Ortuno, A.; Correal, E.; Moraleda, J.M. Furanocoumarins: Biomolecules of therapeutic interest. In Studies in Natural Products Chemistry; Elsevier: Amsterdam, The Netherlands, 2014; Volume 43, pp. $145-195$.

18. Walker, E.H.; Pacold, M.E.; Perisic, O.; Stephens, L.; Hawkins, P.T.; Wymann, M.P.; Williams, R.L. Structural determinants of phosphoinositide 3-kinase inhibition by wortmannin, LY294002, quercetin, myricetin, and staurosporine. Mol. Cell 2000, 6, 909-919. [CrossRef]

19. Han, R.-M.; Tian, Y.-X.; Liu, Y.; Chen, C.-H.; Ai, X.-C.; Zhang, J.-P.; Skibsted, L.H. Comparison of flavonoids and isoflavonoids as antioxidants. J. Agric. Food Chem. 2009, 57, 3780-3785. [CrossRef] [PubMed]

20. Sreevidya, V.; Srinivasa Rao, C.; Sullia, S.; Ladha, J.K.; Reddy, P.M. Metabolic engineering of rice with soybean isoflavone synthase for promoting nodulation gene expression in rhizobia. J. Exp. Bot. 2006, 57, 1957-1969. [CrossRef] 
21. Dixon, R.A.; Ferreira, D. Molecules of Interest: Genistein. ChemInform 2002, 33. [CrossRef]

22. Fine, P.V.; Miller, Z.J.; Mesones, I.; Irazuzta, S.; Appel, H.M.; Stevens, M.H.H.; Sääksjärvi, I.; Schultz, J.C.; Coley, P.D. The growth-defense trade-off and habitat specialization by plants in Amazonian forests. Ecology 2006, 87, S150-S162. [CrossRef]

23. Vranová, E.; Coman, D.; Gruissem, W. Structure and dynamics of the isoprenoid pathway network. Mol. Plant 2012, 5, 318-333. [CrossRef]

24. Moniczewski, A.; Librowski, T.; Lochyński, S.; Strub, D. Evaluation of the irritating influence of carane derivatives and their antioxidant properties in a deoxyribose degradation test. Pharmacol. Rep. 2011, 63, 120-129. [CrossRef]

25. Boncan, D.A.T.; Tsang, S.S.; Li, C.; Lee, I.H.; Lam, H.-M.; Chan, T.-F.; Hui, J.H. Terpenes and Terpenoids in Plants: Interactions with Environment and Insects. Int. J. Mol. Sci. 2020, 21, 7382. [CrossRef]

26. Canales, M.; Hernández, T.; Caballero, J.; De Vivar, A.R.; Avila, G.; Duran, A.; Lira, R. Informant consensus factor and antibacterial activity of the medicinal plants used by the people of San Rafael Coxcatlán, Puebla, México. J. Ethnopharmacol. 2005, 97, 429-439. [CrossRef] [PubMed]

27. Kessler, A.; Baldwin, I.T. Defensive function of herbivore-induced plant volatile emissions in nature. Science 2001, $291,2141-2144$. [CrossRef] [PubMed]

28. Schnall, J.A.; Quatrano, R.S. Abscisic acid elicits the water-stress response in root hairs of Arabidopsis thaliana. Plant Physiol. 1992, 100, 216-218. [CrossRef] [PubMed]

29. Mafu, S.; Zerbe, P. Plant diterpenoid metabolism for manufacturing the biopharmaceuticals of tomorrow: Prospects and challenges. Phytochem. Rev. 2018, 17, 113-130. [CrossRef]

30. Hill, R.A.; Connolly, J.D. Triterpenoids. Nat. Prod. Rep. 2013, 30, 1028-1065. [CrossRef] [PubMed]

31. Breitmaier, E. Terpenes: Flavors, Fragrances, Pharmaca, Pheromones; John Wiley \& Sons: Weinheim, Germany, 2006.

32. Chudzik, M.; Korzonek-Szlacheta, I.; Król, W. Triterpenes as potentially cytotoxic compounds. Molecules 2015, 20 , 1610-1625. [CrossRef]

33. Thimmappa, R.; Geisler, K.; Louveau, T.; O’Maille, P.; Osbourn, A. Triterpene biosynthesis in plants. Annu. Rev. Plant Biol. 2014, 65, 225-257. [CrossRef]

34. Eisner, T.; Meinwald, J. Chemical Ecology: The Chemistry of Biotic Interaction; National Academies Press: Washington, DC, USA, 1995.

35. Benedek, I. Pressure-Sensitive Adhesives and Applications; CRC Press: Boca Raton, FL, USA, 2004.

36. Venditti, A.; Bianco, A. Sulfur-containing secondary metabolites as neuroprotective agents. Curr. Med. Chem. 2020, 27, 4421-4436. [CrossRef]

37. Schnug, E.; Haneklaus, S. Sulphur deficiency symptoms in oilseed rape (Brassica napus L.)-the aesthetics of starvation. Phyton-Horn 2005, 45, 79 .

38. Bloem, E.; Haneklaus, S.; Salac, I.; Wickenhäuser, P.; Schnug, E. Facts and fiction about sulfur metabolism in relation to plant-pathogen interactions. Plant Biol. 2007, 9, 596-607. [CrossRef]

39. Masondo, N.A.; Aremu, A.O.; Finnie, J.F.; Van Staden, J. Plant growth regulator induced phytochemical and antioxidant variations in micropropagated and acclimatized Eucomis autumnalis subspecies autumnalis (Asparagaceae). Acta Physiol. Plant. 2014, 36, 2467-2479. [CrossRef]

40. Llorens-Molina, J.A.; Vacas, S. Effect of drought stress on essential oil composition of Thymus vulgaris L. (Chemotype 1, 8-cineole) from wild populations of Eastern Iberian Peninsula. J. Essent. Oil Res. 2017, 29, 145-155. [CrossRef]

41. Shi, M.; Kwok, K.; Wu, J.Y. Enhancement of tanshinone production in Salvia miltiorrhiza Bunge (red or Chinese sage) hairy-root culture by hyperosmotic stress and yeast elicitor. Biotechnol. Appl. Biochem. 2007, 46, 191-196. [PubMed]

42. Pang, X.-Y.; Wang, S.; Jurczak, M.J.; Shulman, G.I.; Moise, A.R. Retinol saturase modulates lipid metabolism and the production of reactive oxygen species. Arch. Biochem. Biophys. 2017, 633, 93-102. [CrossRef]

43. Munné-Bosch, S.; Mueller, M.; Schwarz, K.; Alegre, L. Diterpenes and antioxidative protection in drought-stressed Salvia officinalis plants. J. Plant Physiol. 2001, 158, 1431-1437. [CrossRef]

44. Spicher, L.; Almeida, J.; Gutbrod, K.; Pipitone, R.; Dörmann, P.; Glauser, G.; Rossi, M.; Kessler, F. Essential role for phytol kinase and tocopherol in tolerance to combined light and temperature stress in tomato. J. Exp. Bot. 2017, 68, 5845-5856. [CrossRef]

45. Lewis, W.; Manony, P. Plants Affecting Mans Health in: Medical Botany; John Willey and Sons: New York, NY, USA, 1997; Volume 240.

46. Jung, H.-Y.; Kang, S.-M.; Kang, Y.-M.; Kang, M.-J.; Yun, D.-J.; Bahk, J.-D.; Yang, J.-K.; Choi, M.-S. Enhanced production of scopolamine by bacterial elicitors in adventitious hairy root cultures of Scopolia parviflora. Enzym. Microb. Technol. 2003, 33, 987-990. [CrossRef]

47. Lin, Y.; Qasim, M.; Hussain, M.; Akutse, K.S.; Avery, P.B.; Dash, C.K.; Wang, L. The herbivore-induced plant volatiles methyl salicylate and menthol positively affect growth and pathogenicity of entomopathogenic fungi. Sci. Rep. 2017, 7, 40494. [CrossRef]

48. Schweiger, R.; Baier, M.C.; Persicke, M.; Müller, C. High specificity in plant leaf metabolic responses to arbuscular mycorrhiza. Nat. Commun. 2014, 5, 3886. [CrossRef]

49. Ahmed, E.; Arshad, M.; Khan, M.Z.; Amjad, H.S.; Sadaf, H.M.; Riaz, I.; Sabir, S.; Ahmad, N. Secondary metabolites and their multidimensional prospective in plant life. J. Pharmacogn. Phytochem. 2017, 6, 205-214.

50. Brown, G.D. The biosynthesis of artemisinin (Qinghaosu) and the phytochemistry of Artemisia annua L. (Qinghao). Molecules 2010, 15, 7603-7698. [CrossRef] [PubMed]

51. Tian, X.; Fang, X.; Huang, J.-Q.; Wang, L.-J.; Mao, Y.-B.; Chen, X.-Y. A gossypol biosynthetic intermediate disturbs plant defence response. Philos. Trans. R. Soc. B 2019, 374, 20180319. [CrossRef] 
52. Fournier, A.R.; Proctor, J.T.; Gauthier, L.; Khanizadeh, S.; Belanger, A.; Gosselin, A.; Dorais, M. Understory light and root ginsenosides in forest-grown Panax quinquefolius. Phytochemistry 2003, 63, 777-782. [CrossRef]

53. Abe, I. Enzymatic synthesis of cyclic triterpenes. Nat. Prod. Rep. 2007, 24, 1311-1331. [CrossRef]

54. Li, X.; Lv, X.; Wang, X.; Wang, L.; Zhang, M.; Ren, M. Effects of abiotic stress on anthocyanin accumulation and grain weight in purple wheat. Crop Pasture Sci. 2019, 69, 1208-1214. [CrossRef]

55. Hou, D.-X.; Fujii, M.; Terahara, N.; Yoshimoto, M. Molecular mechanisms behind the chemopreventive effects of anthocyanidins. J. Biomed. Biotechnol. 2004, 2004, 321. [CrossRef]

56. Jain, A.; Singh, A.; Singh, S.; Singh, H.B. Phenols enhancement effect of microbial consortium in pea plants restrains Sclerotinia sclerotiorum. Biol. Control 2015, 89, 23-32. [CrossRef]

57. Reiter, R.; Paredes, S.; Korkmaz, A.; Jou, M.-J.; Tan, D.-X. Melatonin combats molecular terrorism at the mitochondrial level. Interdiscip. Toxicol. 2008, 1, 137-149. [CrossRef] [PubMed]

58. Aziz, M.; Sturtevant, D.; Winston, J.; Collakova, E.; Jelesko, J.G.; Chapman, K.D. MALDI-MS imaging of urushiols in poison ivy stem. Molecules 2017, 22, 711. [CrossRef]

59. Griffith, M.; Yaish, M.W. Antifreeze proteins in overwintering plants: A tale of two activities. Trends Plant Sci. 2004, 9, 399-405. [CrossRef]

60. Petridis, A.; Therios, I.; Samouris, G.; Tananaki, C. Salinity-induced changes in phenolic compounds in leaves and roots of four olive cultivars (Olea europaea L.) and their relationship to antioxidant activity. Environ. Exp. Bot. 2012, 79, 37-43. [CrossRef]

61. Mishra, R.P.; Singh, R.K.; Jaiswal, H.K.; Kumar, V.; Maurya, S. Rhizobium-mediated induction of phenolics and plant growth promotion in rice (Oryza sativa L.). Curr. Microbiol. 2006, 52, 383-389. [CrossRef] [PubMed]

62. Gan, R.-Y.; Kong, K.-W.; Li, H.-B.; Wu, K.; Ge, Y.-Y.; Chan, C.-L.; Shi, X.-M.; Corke, H. Separation, identification, and bioactivities of the main gallotannins of red sword bean (Canavalia gladiata) coats. Front. Chem. 2018, 6, 39. [CrossRef]

63. Wang, Q.; Eneji, A.E.; Kong, X.; Wang, K.; Dong, H. Salt stress effects on secondary metabolites of cotton in relation to gene expression responsible for aphid development. PLoS ONE 2015, 10, e0129541. [CrossRef]

64. Stringlis, I.A.; De Jonge, R.; Pieterse, C.M. The age of coumarins in plant-microbe interactions. Plant Cell Physiol. 2019, 60, 1405-1419. [CrossRef] [PubMed]

65. Ahmed, S.A.; Baig, M.M.V. Biotic elicitor enhanced production of psoralen in suspension cultures of Psoralea corylifolia L. Saudi J. Biol. Sci. 2014, 21, 499-504. [CrossRef]

66. Aldulaimi, O. Screening of fruits of seven plants indicated for medicinal use in Iraq. Pharmacogn. Mag. 2017, 13, S189. [CrossRef] [PubMed]

67. Özçelik, B.; Kartal, M.; Orhan, I. Cytotoxicity, antiviral and antimicrobial activities of alkaloids, flavonoids, and phenolic acids. Pharm. Biol. 2011, 49, 396-402. [CrossRef] [PubMed]

68. Chi, W.-C.; Fu, S.-F.; Huang, T.-L.; Chen, Y.-A.; Chen, C.-C.; Huang, H.-J. Identification of transcriptome profiles and signaling pathways for the allelochemical juglone in rice roots. Plant Mol. Biol. 2011, 77, 591-607. [CrossRef] [PubMed]

69. Komaraiah, P.; Ramakrishna, S.; Reddanna, P.; Kishor, P.K. Enhanced production of plumbagin in immobilized cells of Plumbago rosea by elicitation and in situ adsorption. J. Biotechnol. 2003, 101, 181-187. [CrossRef]

70. Izhaki, I. Emodin-A secondary metabolite with multiple ecological functions in higher plants. New Phytol. 2002, 155, 205-217. [CrossRef]

71. Sarker, U.; Oba, S. Augmentation of leaf color parameters, pigments, vitamins, phenolic acids, flavonoids and antioxidant activity in selected Amaranthus tricolor under s alinity stress. Sci. Rep. 2018, 8, 12349. [CrossRef]

72. Hodaei, M.; Rahimmalek, M.; Arzani, A.; Talebi, M. The effect of water stress on phytochemical accumulation, bioactive compounds and expression of key genes involved in flavonoid biosynthesis in Chrysanthemum morifolium L. Ind. Crop. Prod. 2018, 120, 295-304. [CrossRef]

73. Pushpalatha, H.B.; Pramod, K.; Devanathan, R.; Sundaram, R. Use of bergenin as an analytical marker for standardization of the polyherbal formulation containing Saxifraga ligulata. Pharmacogn. Mag. 2015, 11, S60. [CrossRef]

74. Muhaimin, S.; Chaerunisaa, A.Y.; Sinaga, M.S. Eusiderin I from Eusideroxylon zwagery as antifungal agent against plant pathogenic fungus. Int. J. Chemtech Res. 2016, 9, 418-424.

75. Luo, F.; Lv, Q.; Zhao, Y.; Hu, G.; Huang, G.; Zhang, J.; Sun, C.; Li, X.; Chen, K. Quantification and purification of mangiferin from Chinese mango (Mangifera indica L.) cultivars and its protective effect on human umbilical vein endothelial cells under H2O2-induced stress. Int. J. Mol. Sci. 2012, 13, 11260-11274. [CrossRef] [PubMed]

76. Yu, S.; Yan, H.; Zhang, L.; Shan, M.; Chen, P.; Ding, A.; Li, S.F.Y. A review on the phytochemistry, pharmacology, and pharmacokinetics of amentoflavone, a naturally-occurring biflavonoid. Molecules 2017, 22, 299. [CrossRef] [PubMed]

77. Andrade, A.W.L.; Figueiredo, D.D.R.; Islam, M.T.; Nunes, A.M.V.; da Conceição Machado, K.; da Conceição Machado, K.; Uddin, S.J.; Shilpi, J.A.; Rouf, R.; de Carvalho Melo-Cavalcante, A.A. Toxicological evaluation of the biflavonoid, agathisflavone in albino Swiss mice. Biomed. Pharmacother. 2019, 110, 68-73. [CrossRef]

78. Thomma, B.P.; Cammue, B.P.; Thevissen, K. Plant defensins. Planta 2002, 216, 193-202. [CrossRef]

79. Abdalla, M.A.; Mühling, K.H. Plant-derived sulfur containing natural products produced as a response to biotic and abiotic stresses: A review of their structural diversity and medicinal importance. J. Appl. Bot. Food Qual. 2009, 92, $204-215$.

80. Pedras, M.S.C.; Zheng, Q.-A.; Schatte, G.; Adio, A.M. Photochemical dimerization of wasalexins in UV-irradiated Thellungiella halophila and in vitro generates unique cruciferous phytoalexins. Phytochemistry 2009, 70, 2010-2016. [CrossRef] 
81. Moreira-Rodríguez, M.; Nair, V.; Benavides, J.; Cisneros-Zevallos, L.; Jacobo-Velázquez, D.A. UVA, UVB light, and methyl jasmonate, alone or combined, redirect the biosynthesis of glucosinolates, phenolics, carotenoids, and chlorophylls in broccoli sprouts. Int. J. Mol. Sci. 2017, 18, 2330. [CrossRef] [PubMed]

82. Villarreal-García, D.; Nair, V.; Cisneros-Zevallos, L.; Jacobo-Velázquez, D.A. Plants as biofactories: Postharvest stress-induced accumulation of phenolic compounds and glucosinolates in broccoli subjected to wounding stress and exogenous phytohormones. Front. Plant Sci. 2016, 7, 45. [CrossRef] [PubMed]

83. Martínez-Ballesta, M.d.C.; Muries, B.; Moreno, D.Á.; Dominguez-Perles, R.; García-Viguera, C.; Carvajal, M. Involvement of a glucosinolate (sinigrin) in the regulation of water transport in Brassica oleracea grown under salt stress. Physiol. Plant. 2014, 150, 145-160. [CrossRef]

84. Szabó, B.; Tyihák, E.; Szabó, G.; Botz, L. Mycotoxin and drought stress induced change of alkaloid content of Papaver somniferum plantlets. Acta Bot. Hung. 2003, 45, 409-417. [CrossRef]

85. Irmer, S.; Podzun, N.; Langel, D.; Heidemann, F.; Kaltenegger, E.; Schemmerling, B.; Geilfus, C.-M.; Zörb, C.; Ober, D. New aspect of plant-rhizobia interaction: Alkaloid biosynthesis in Crotalaria depends on nodulation. Proc. Natl. Acad. Sci. USA 2015, 112, 4164-4169. [CrossRef] [PubMed]

86. Rivero, J.; Álvarez, D.; Flors, V.; Azcón-Aguilar, C.; Pozo, M.J. Root metabolic plasticity underlies functional diversity in mycorrhiza-enhanced stress tolerance in tomato. New Phytol. 2018, 220, 1322-1336. [CrossRef]

87. Hill, E.M.; Robinson, L.A.; Abdul-Sada, A.; Vanbergen, A.J.; Hodge, A.; Hartley, S.E. Arbuscular mycorrhizal fungi and plant chemical defence: Effects of colonisation on aboveground and belowground metabolomes. J. Chem. Ecol. 2018, 44, 198-208. [CrossRef]

88. Binder, B.Y.; Peebles, C.A.; Shanks, J.V.; San, K.Y. The effects of UV-B stress on the production of terpenoid indole alkaloids in Catharanthus roseus hairy roots. Biotechnol. Prog. 2009, 25, 861-865. [CrossRef]

89. Hartmann, T.; Ober, D. Biosynthesis and metabolism of pyrrolizidine alkaloids in plants and specialized insect herbivores. In Biosynthesis; Springer: Heidelberg, Berlin, 2000; pp. 207-243.

90. Xuan, T.; Elzaawely, A.; Deba, F.; Fukuta, M.; Tawata, S. Mimosine in Leucaena as a potent bio-herbicide. Agron. Sustain. Dev. 2006, 26, 89-97. [CrossRef]

91. Yokota, A.; Kawasaki, S.; Iwano, M.; Nakamura, C.; Miyake, C.; Akashi, K. Citrulline and DRIP-1 protein (ArgE homologue) in drought tolerance of wild watermelon. Ann. Bot. 2002, 89, 825-832. [CrossRef]

92. Moulin, M.; Deleu, C.; Larher, F.; Bouchereau, A. The lysine-ketoglutarate reductase-saccharopine dehydrogenase is involved in the osmo-induced synthesis of pipecolic acid in rapeseed leaf tissues. Plant Physiol. Biochem. 2006, 44, 474-482. [CrossRef] [PubMed]

93. Emendack, Y.; Burke, J.; Laza, H.; Sanchez, J.; Hayes, C. Abiotic stress effects on sorghum leaf dhurrin and soluble sugar contents throughout plant development. Crop Sci. 2018, 58, 1706-1716. [CrossRef]

94. Lai, D.; Pičmanová, M.; Abou Hachem, M.; Motawia, M.S.; Olsen, C.E.; Møller, B.L.; Rook, F.; Takos, A.M. Lotus japonicus flowers are defended by a cyanogenic $\beta$-glucosidase with highly restricted expression to essential reproductive organs. Plant Mol. Biol. 2015, 89, 21-34. [CrossRef] [PubMed]

95. Seigler, D.S. Plant Secondary Metabolism; Springer Science \& Business Media: Dordrecht, The Netherland, 2012.

96. Verma, N.; Shukla, S. Impact of various factors responsible for fluctuation in plant secondary metabolites. J. Appl. Res. Med. Aromat. Plants 2015, 2, 105-113. [CrossRef]

97. Griesser, M.; Weingart, G.; Schoedl-Hummel, K.; Neumann, N.; Becker, M.; Varmuza, K.; Liebner, F.; Schuhmacher, R.; Forneck, A. Severe drought stress is affecting selected primary metabolites, polyphenols, and volatile metabolites in grapevine leaves (Vitis vinifera cv. Pinot noir). Plant Physiol. Biochem. 2015, 88, 17-26. [CrossRef]

98. Karwasara, V.S.; Dixit, V.K. Culture medium optimization for camptothecin production in cell suspension cultures of Nothapodytes nimmoniana (J. Grah.) Mabberley. Plant Biotechnol. Rep. 2013, 7, 357-369. [CrossRef]

99. Zu, Y.-G.; Tang, Z.-H.; Yu, J.-H.; Liu, S.-G.; Wang, W.; Guo, X.-R. Different responses of camptothecin and 10-hydroxycamptothecin to heat shock in Camptotheca acuminata seedlings. J. Integr. Plant Biol. 2003, 45, 809-814.

100. Jansen, G.; Jürgens, H.U.; Ordon, F. Effects of temperature on the alkaloid content of seeds of Lupinus angustifolius cultivars. J. Agron. Crop Sci. 2009, 195, 172-177. [CrossRef]

101. Dutta, A.; Sen, J.; Deswal, R. Downregulation of terpenoid indole alkaloid biosynthetic pathway by low temperature and cloning of a AP2 type C-repeat binding factor (CBF) from Catharanthus roseus (L). G. Don. Plant Cell Rep. 2007, 26, 1869-1878. [CrossRef]

102. Hanson, D.; Sharkey, T.D. Effect of growth conditions on isoprene emission and other thermotolerance-enhancing compounds. Plantcell Environ. 2001, 24, 929-936. [CrossRef]

103. Zhao, Y.; Jia, X.; Wang, W.; Liu, T.; Huang, S.; Yang, M. Growth under elevated air temperature alters secondary metabolites in Robinia pseudoacacia L. seedlings in Cd-and Pb-contaminated soils. Sci. Total Environ. 2016, 565, 586-594. [CrossRef]

104. Edreva, A.; Velikova, V.; Tsonev, T.; Dagnon, S.; Gürel, A.; Aktaş, L.; Gesheva, E. Stress-protective role of secondary metabolites: Diversity of functions and mechanisms. Gen. Appl. Plant Physiol. 2008, 34, 67-78.

105. Chan, L.; Koay, S.; Boey, P.; Bhatt, A. Effects of abiotic stress on biomass and anthocyanin production in cell cultures of Melastoma malabathricum. Biol. Res. 2010, 43, 127-135. [CrossRef]

106. Hossain, M.S.; Persicke, M.; ElSayed, A.I.; Kalinowski, J.; Dietz, K.-J. Metabolite profiling at the cellular and subcellular level reveals metabolites associated with salinity tolerance in sugar beet. J. Exp. Bot. 2017, 68, 5961-5976. [CrossRef] 
107. Manuka, R.; Karle, S.B.; Kumar, K. OsWNK9 mitigates salt and drought stress effects through induced antioxidant systems in Arabidopsis. Plant Physiol. Rep. 2019, 24, 168-181. [CrossRef]

108. Adak, S.; Roy, A.; Das, P.; Mukherjee, A.; Sengupta, S.; Majumder, A.L. Soil salinity and mechanical obstruction differentially affects embryonic root architecture in different rice genotypes from West Bengal. Plant Physiol. Rep. 2019, 24, 192-209. [CrossRef]

109. Xu, C.; Tang, X.; Shao, H.; Wang, H. Salinity tolerance mechanism of economic halophytes from physiological to molecular hierarchy for improving food quality. Curr. Genom. 2016, 17, 207-214. [CrossRef] [PubMed]

110. Bourgaud, F.; Gravot, A.; Milesi, S.; Gontier, E. Production of plant secondary metabolites: A historical perspective. Plant Sci. 2001, 161, 839-851. [CrossRef]

111. Daneshmand, F.; Arvin, M.J.; Kalantari, K.M. Physiological responses to $\mathrm{NaCl}$ stress in three wild species of potato in vitro. Acta Physiol. Plant. 2010, 32, 91. [CrossRef]

112. Parida, A.K.; Das, A.B. Salt tolerance and salinity effects on plants: A review. Ecotoxicol. Environ. Saf. 2005, 60, 324-349. [CrossRef]

113. Navarro, J.M.; Flores, P.; Garrido, C.; Martinez, V. Changes in the contents of antioxidant compounds in pepper fruits at different ripening stages, as affected by salinity. Food Chem. 2006, 96, 66-73. [CrossRef]

114. Slama, I.; M'Rabet, R.; Ksouri, R.; Talbi, O.; Debez, A.; Abdelly, C. Effects of salt treatment on growth, lipid membrane peroxidation, polyphenol content, and antioxidant activities in leaves of Sesuvium portulacastrum L. Arid Land Res. Manag. 2017, 31, 404-417. [CrossRef]

115. Mashilo, J.; Odindo, A.O.; Shimelis, H.A.; Musenge, P.; Tesfay, S.Z.; Magwaza, L.S. Drought tolerance of selected bottle gourd [Lagenaria siceraria (Molina) Standl.] landraces assessed by leaf gas exchange and photosynthetic efficiency. Plant Physiol. Biochem. 2017, 120, 75-87. [CrossRef] [PubMed]

116. Isah, T. Stress and defense responses in plant secondary metabolites production. Biol. Res. 2019, 52, 39. [CrossRef]

117. Dawid, C.; Hille, K. Functional metabolomics-A useful tool to characterize stress-induced metabolome alterations opening new avenues towards tailoring food crop quality. Agronomy 2018, 8, 138. [CrossRef]

118. Yuan, Y.; Liu, Y.; Wu, C.; Chen, S.; Wang, Z.; Yang, Z.; Qin, S.; Huang, L. Water deficit affected flavonoid accumulation by regulating hormone metabolism in Scutellaria baicalensis Georgi roots. PLoS ONE 2012, 7, e42946. [CrossRef]

119. Délano-Frier, J.P.; Avilés-Arnaut, H.; Casarrubias-Castillo, K.; Casique-Arroyo, G.; Castrillón-Arbeláez, P.A.; Herrera-Estrella, L.; Massange-Sánchez, J.; Martínez-Gallardo, N.A.; Parra-Cota, F.I.; Vargas-Ortiz, E. Transcriptomic analysis of grain amaranth (Amaranthus hypochondriacus) using 454 pyrosequencing: Comparison with A. tuberculatus, expression profiling in stems and in response to biotic and abiotic stress. BMC Genom. 2011, 12, 363. [CrossRef] [PubMed]

120. Solíz-Guerrero, J.B.; De Rodriguez, D.J.; Rodríguez-García, R.; Angulo-Sánchez, J.L.; Méndez-Padilla, G. Quinoa saponins: Concentration and composition analysis. In Trends in New Crops and New Uses; ASHS Press: Alexandria, VA, USA, 2002; pp. 110-114.

121. Ghosh, S.; Watson, A.; Gonzalez-Navarro, O.E.; Ramirez-Gonzalez, R.H.; Yanes, L.; Mendoza-Suárez, M.; Simmonds, J.; Wells, R.; Rayner, T.; Green, P. Speed breeding in growth chambers and glasshouses for crop breeding and model plant research. Nat. Protoc. 2018, 13, 2944-2963. [CrossRef] [PubMed]

122. Deepthi, S.; Satheeshkumar, K. Effects of major nutrients, growth regulators and inoculum size on enhanced growth and camptothecin production in adventitious root cultures of Ophiorrhiza mungos L. Biochem. Eng. J. 2017, 117, 198-209. [CrossRef]

123. Cingöz, G.; Karakaş, F.P. The effects of nutrient and macronutrient stress on certain secondary metabolite accumulations and redox regulation in callus cultures of Bellis perennis L. Turk. J. Biol. 2016, 40, 1328-1335. [CrossRef]

124. Turtola, S.; Manninen, A.-M.; Rikala, R.; Kainulainen, P. Drought stress alters the concentration of wood terpenoids in Scots pine and Norway spruce seedlings. J. Chem. Ecol. 2003, 29, 1981-1995. [CrossRef] [PubMed]

125. Carvalho, R.F.; Takaki, M.; Azevedo, R.A. Plant pigments: The many faces of light perception. Acta Physiol. Plant. 2011, 33, 241-248. [CrossRef]

126. Zoratti, L.; Karppinen, K.; Luengo Escobar, A.; Häggman, H.; Jaakola, L. Light-controlled flavonoid biosynthesis in fruits. Front. Plant Sci. 2014, 5, 534. [CrossRef] [PubMed]

127. Waterman, P.G.; Mole, S. Extrinsic factors influencing production of secondary metabolites in plants. Insect-Plant Interact. 1989, 1, 107-134.

128. Hirata, K.; Asada, M.; Yatani, E.; Miyamoto, K.; Miura, Y. Effects of near-ultraviolet light on alkaloid production in Catharanthus roseus plants. Planta Med. 1993, 59, 46-50. [CrossRef]

129. Morales, L.O.; Tegelberg, R.; Brosché, M.; Keinänen, M.; Lindfors, A.; Aphalo, P.J. Effects of solar UV-A and UV-B radiation on gene expression and phenolic accumulation in Betula pendula leaves. Tree Physiol. 2010, 30, 923-934. [CrossRef]

130. Gouvea, D.R.; Gobbo-Neto, L.; Lopes, N.P. The influence of biotic and abiotic factors on the production of secondary metabolites in medicinal plants. Plant Bioact. Drug Discov. Princ. Pract. Perspect. 2012, 17, 419-452.

131. Jaakola, L.; Hohtola, A. Effect of latitude on flavonoid biosynthesis in plants. Plantcell Environ. 2010, 33, 1239-1247. [CrossRef] [PubMed]

132. Yang, B.; Zheng, J.; Laaksonen, O.; Tahvonen, R.; Kallio, H. Effects of latitude and weather conditions on phenolic compounds in currant (Ribes spp.) cultivars. J. Agric. Food Chem. 2013, 61, 3517-3532. [CrossRef] [PubMed]

133. Taylor, A. Some effects of photoperiod on the biosynthesis of phenylpropane derivatives in Xanthium. Plant Physiol. 1965, 40, 273. [CrossRef] 
134. Camm, E.; McCallum, J.; Leaf, E.; Koupai-Abyazani, M. Cold-induced purpling of Pinus contorta seedlings depends on previous daylength treatment. Plantcell Environ. 1993, 16, 761-764. [CrossRef]

135. Carvalho, I.S.; Cavaco, T.; Carvalho, L.M.; Duque, P. Effect of photoperiod on flavonoid pathway activity in sweet potato (Ipomoea batatas (L.) Lam.) leaves. Food Chem. 2010, 118, 384-390. [CrossRef]

136. Kliewer, W.M. Influence of temperature, solar radiation and nitrogen on coloration and composition of Emperor grapes. Am. J. Enol. Vitic. 1977, 28, 96-103.

137. Antognoni, F.; Zheng, S.; Pagnucco, C.; Baraldi, R.; Poli, F.; Biondi, S. Induction of flavonoid production by UV-B radiation in Passiflora quadrangularis callus cultures. Fitoterapia 2007, 78, 345-352. [CrossRef] [PubMed]

138. Broeckling, C.D.; Huhman, D.V.; Farag, M.A.; Smith, J.T.; May, G.D.; Mendes, P.; Dixon, R.A.; Sumner, L.W. Metabolic profiling of Medicago truncatula cell cultures reveals the effects of biotic and abiotic elicitors on metabolism. J. Exp. Bot. 2005, 56, 323-336. [CrossRef]

139. Ku, K.-L.; Chang, P.-S.; Cheng, Y.-C.; Lien, C.-Y. Production of stilbenoids from the callus of Arachis hypogaea: A novel source of the anticancer compound piceatannol. J. Agric. Food Chem. 2005, 53, 3877-3881. [CrossRef]

140. Ramani, S.; Jayabaskaran, C. Enhanced catharanthine and vindoline production in suspension cultures of Catharanthus roseus by ultraviolet-B light. J. Mol. Signal. 2008, 3, 9. [CrossRef] [PubMed]

141. Regvar, M.; Bukovnik, U.; Likar, M.; Kreft, I. UV-B radiation affects flavonoids and fungal colonisation in Fagopyrum esculentum and F. tataricum. Open Life Sci. 2012, 7, 275-283. [CrossRef]

142. Swanepoel, J.; Krüger, G.; Van Heerden, P. Effects of sulphur dioxide on photosynthesis in the succulent Augea capensis Thunb. J. Arid Environ. 2007, 70, 208-221. [CrossRef]

143. Chung, C.-Y.; Chung, P.-L.; Liao, S.-W. Carbon fixation efficiency of plants influenced by sulfur dioxide. Environ. Monit. Assess. 2011, 173, 701-707. [CrossRef]

144. Da Silva, L.C.; de Araújo, T.O.; Martinez, C.A.; de Almeida Lobo, F.; Azevedo, A.A.; Oliva, M.A. Differential responses of C 3 and CAM native Brazilian plant species to a SO 2-and SPM Fe-contaminated Restinga. Environ. Sci. Pollut. Res. 2015, 22, 14007-14017. [CrossRef] [PubMed]

145. Falk, K.L.; Tokuhisa, J.G.; Gershenzon, J. The effect of sulfur nutrition on plant glucosinolate content: Physiology and molecular mechanisms. Plant Biol. 2007, 9, 573-581. [CrossRef]

146. Giraud, E.; Ivanova, A.; Gordon, C.S.; Whelan, J.; Considine, M.J. Sulphur dioxide evokes a large scale reprogramming of the grape berry transcriptome associated with oxidative signalling and biotic defence responses. Plantcell Environ. $2012,35,405-417$. [CrossRef]

147. Montesinos-Pereira, D.; Barrameda-Medina, Y.; Baenas, N.; Moreno, D.A.; Sanchez-Rodriguez, E.; Blasco, B.; Ruiz, J.M. Evaluation of hydrogen sulfide supply to biostimulate the nutritive and phytochemical quality and the antioxidant capacity of Cabbage (Brassica oleracea L.'Bronco'). J. Appl. Bot Food Qual. 2016, 89, 290-298.

148. Cai, Z.; Kastell, A.; Speiser, C.; Smetanska, I. Enhanced resveratrol production in Vitis vinifera cell suspension cultures by heavy metals without loss of cell viability. Appl. Biochem. Biotechnol. 2013, 171, 330-340. [CrossRef]

149. Nasim, S.A.; Dhir, B. Heavy metals alter the potency of medicinal plants. In Reviews of Environmental Contamination and Toxicology; Springer: New York, NY, USA, 2010; pp. 139-149.

150. Verpoorte, R.; Contin, A.; Memelink, J. Biotechnology for the production of plant secondary metabolites. Phytochem. Rev. 2002, 1, 13-25. [CrossRef]

151. Zhao, J.; Zhu, W.-H.; Hu, Q. Selection of fungal elicitors to increase indole alkaloid accumulation in Catharanthus roseus suspension cell culture. Enzym. Microb. Technol. 2001, 28, 666-672. [CrossRef]

152. Singh, S.; Sinha, S. Accumulation of metals and its effects in Brassica juncea (L.) Czern.(cv. Rohini) grown on various amendments of tannery waste. Ecotoxicol. Environ. Saf. 2005, 62, 118-127. [CrossRef]

153. Mizukami, H.; Konoshima, M.; Tabata, M. Effect of nutritional factors on shikonin derivative formation in Lithospermum callus cultures. Phytochemistry 1977, 16, 1183-1186. [CrossRef]

154. Ohlsson, A.B.; Berglund, T. Effects of high MnSO4 levels on cardenolide accumulation by Digitalis lanata tissue cultures in light and darkness. J. Plant Physiol. 1989, 135, 505-507. [CrossRef]

155. Trejo-Tapia, G.; Jimenez-Aparicio, A.; Rodriguez-Monroy, M.; De Jesus-Sanchez, A.; Gutierrez-Lopez, G. Influence of cobalt and other microelements on the production of betalains and the growth of suspension cultures of Beta vulgaris. Plant Celltissue Organ Cult. 2001, 67, 19-23. [CrossRef]

156. Saba; Pande, D.; Iqbal, M.; Srivastava, P.S. Effect of $\mathrm{ZnSO}_{4}$ and $\mathrm{CuSO}_{4}$ on Regeneration and Lepidine Content in Lepidium Sativum L. Biol. Plant. 2000, 43, 253-256. [CrossRef]

157. Angelova, Z.; Georgiev, S.; Roos, W. Elicitation of Plants. Biotechnol. Biotechnol. Equip. 2006, 20, 72-83. [CrossRef]

158. Pitta-Alvarez, S.I.; Spollansky, T.C.; Giulietti, A.M. The influence of different biotic and abiotic elicitors on the production and profile of tropane alkaloids in hairy root cultures of Brugmansia candida. Enzym. Microb. Technol. 2000, 26, 252-258. [CrossRef]

159. Mahmood, I.; Imadi, S.R.; Shazadi, K.; Gul, A.; Hakeem, K.R. Effects of Pesticides on Environment. In Plant, Soil and Microbes: Volume 1: Implications in Crop Science; Hakeem, K.R., Akhtar, M.S., Abdullah, S.N.A., Eds.; Springer: Cham, Switzerland, 2016; pp. 253-269.

160. Cooper, J.; Dobson, H. The benefits of pesticides to mankind and the environment. Crop Prot. 2007, 26, 1337-1348. [CrossRef] 
161. Chaudhary, N.; Choudhary, K.K.; Agrawal, S.; Agrawal, M. Pesticides Usage, Uptake and Mode of Action in Plants with Special Emphasis on Photosynthetic Characteristics. Pestic. Crop Prod. Physiol. Biochem. Action 2020, 159-180. [CrossRef]

162. Pereira, S.I.; Figueiredo, P.I.; Barros, A.S.; Dias, M.C.; Santos, C.; Duarte, I.F.; Gil, A.M. Changes in the metabolome of lettuce leaves due to exposure to mancozeb pesticide. Food Chem. 2014, 154, 291-298. [CrossRef]

163. Lydon, J.; Duke, S.O. Pesticide effects on secondary metabolism of higher plants. Pestic. Sci. 1989, 25, 361-373. [CrossRef]

164. Cullen, M.G.; Thompson, L.J.; Carolan, J.C.; Stout, J.C.; Stanley, D.A. Fungicides, herbicides and bees: A systematic review of existing research and methods. PLoS ONE 2019, 14, e0225743. [CrossRef]

165. Geetha, A. Chapter-2 Phytotoxicity Due to Fungicides and Herbicides and Its Impact in Crop Physiological Factors. In Advances in Agriculture Sciences; AkiNik Publications: Delhi, India, 2019; p. 29.

166. Blossey, B.; Hunt-Joshi, T.R. Belowground herbivory by insects: Influence on plants and aboveground herbivores. Annu. Rev. Entomol. 2003, 48, 521-547. [CrossRef]

167. Levin, D.A. Plant phenolics: An ecological perspective. Am. Nat. 1971, 105, 157-181. [CrossRef]

168. Friend, J. Phenolic substances and plant disease. In Biochemistry of Plant Phenolics; Springer: New York, NY, USA, 1979; pp. 557-588.

169. Cook, R.J. Making greater use of introduced microorganisms for biological control of plant pathogens. Annu. Rev. Phytopathol. 1993, 31, 53-80. [CrossRef] [PubMed]

170. McCartney, H.A.; Foster, S.J.; Fraaije, B.A.; Ward, E. Molecular diagnostics for fungal plant pathogens. Pest Manag. Sci. Former. Pestic. Sci. 2003, 59, 129-142. [CrossRef]

171. Shoresh, M.; Harman, G.E.; Mastouri, F. Induced systemic resistance and plant responses to fungal biocontrol agents. Annu. Rev. Phytopathol. 2010, 48, 21-43. [CrossRef] [PubMed]

172. Dzhavakhiya, V.; Shcherbakova, L. Creation of disease-resistant plants by gene engineering. In Comprehensive and Molecular Phytopathology; Elsevier: Amsterdam, The Netherland; Oxford, UK, 2007; pp. 439-466.

173. Hu, X.; Neill, S.; Cai, W.; Tang, Z. Hydrogen peroxide and jasmonic acid mediate oligogalacturonic acid-induced saponin accumulation in suspension-cultured cells of Panax ginseng. Physiol. Plant. 2003, 118, 414-421. [CrossRef]

174. Fukui, H.; Yoshikawa, N.; Tabata, M. Induction of shikonin formation by agar in Lithospermum erythrorhizon cell suspension cultures. Phytochemistry 1983, 22, 2451-2453. [CrossRef]

175. Orlita, A.; Sidwa-Gorycka, M.; Paszkiewicz, M.; Malinski, E.; Kumirska, J.; Siedlecka, E.M.; Łojkowska, E.; Stepnowski, P. Application of chitin and chitosan as elicitors of coumarins and furoquinolone alkaloids in Ruta graveolens L.(common rue). Biotechnol. Appl. Biochem. 2008, 51, 91-96. [CrossRef] [PubMed]

176. Taurino, M.; Ingrosso, I.; D’amico, L.; De Domenico, S.; Nicoletti, I.; Corradini, D.; Santino, A.; Giovinazzo, G. Jasmonates elicit different sets of stilbenes in Vitis vinifera cv. Negramaro cell cultures. SpringerPlus 2015, 4, 49. [CrossRef]

177. Simic, S.G.; Tusevski, O.; Maury, S.; Delaunay, A.; Lainé, E.; Joseph, C.; Hagège, D. Polysaccharide elicitors enhance phenylpropanoid and naphtodianthrone production in cell suspension cultures of Hypericum perforatum. Plant Celltissue Organ Cult. (PCTOC) 2015, 122, 649-663. [CrossRef]

178. Stangarlin, J.; Kuhn, O.; Assi, L.; Schwan-Estrada, K. Control of plant diseases using extracts from medicinal plants and fungi. Sci. Microb. Pathog. Commun. Curr. Res. Technol. Advances. Badajoz Formatex 2011, 2, 1033-1042.

179. Zaker, A.; Sykora, C.; Gössnitzer, F.; Abrishamchi, P.; Asili, J.; Mousavi, S.H.; Wawrosch, C. Effects of some elicitors on tanshinone production in adventitious root cultures of Perovskia abrotanoides Karel. Ind. Crop. Prod. 2015, 67, 97-102. [CrossRef]

180. Lattanzio, V.; Lattanzio, V.M.; Cardinali, A. Role of phenolics in the resistance mechanisms of plants against fungal pathogens and insects. Phytochem. Adv. Res. 2006, 661, 23-67.

181. Boerema, G.H. Phoma Identification Manual: Differentiation of Specific and Infra-Specific Taxa in Culture; CABI: Wallingford, UK, 2004.

182. Hano, C.; Addi, M.; Bensaddek, L.; Crônier, D.; Baltora-Rosset, S.; Doussot, J.; Maury, S.; Mesnard, F.; Chabbert, B.; Hawkins, S. Differential accumulation of monolignol-derived compounds in elicited flax (Linum usitatissimum) cell suspension cultures. Planta 2006, 223, 975-989. [CrossRef]

183. Sang, M.K.; Kim, J.-G.; Kim, K.D. Biocontrol activity and induction of systemic resistance in pepper by compost water extracts against Phytophthora capsici. Phytopathology 2010, 100, 774-783. [CrossRef]

184. Namdeo, A.; Patil, S.; Fulzele, D.P. Influence of fungal elicitors on production of ajmalicine by cell cultures of Catharanthus roseus. Biotechnol. Prog. 2002, 18, 159-162. [CrossRef]

185. Parchmann, S.; Gundlach, H.; Mueller, M.J. Induction of 12-oxo-phytodienoic acid in wounded plants and elicited plant cell cultures. Plant Physiol. 1997, 115, 1057-1064. [CrossRef]

186. Rokem, J.; Schwarzberg, J.; Goldberg, I. Autoclaved fungal mycelia increase diosgenin production in cell suspension cultures of Dioscorea deltoidea. Plant Cell Rep. 1984, 3, 159-160. [CrossRef]

187. Balazová, A.; Bilka, F.; Blanáriková, V.; Psenák, M. Effect of a fungal elicitor on levels of sanguinarine and polyphenoloxidase activity in a suspension culture of Papaver somniferum L. Ceska A Slov. Farm. Cas. Ceske Farm. Spol. A Slov. Farm. Spol. 2002, $51,182-185$.

188. Eilert, U.; Ehmke, A.; Wolters, B. Elicitor-induced accumulation of acridone alkaloid epoxides in Ruta graveolens suspension cultures. Planta Med. 1984, 50, 508-512. [CrossRef]

189. Awad, V.; Kuvalekar, A.; Harsulkar, A. Microbial elicitation in root cultures of Taverniera cuneifolia (Roth) Arn. for elevated glycyrrhizic acid production. Ind. Crop. Prod. 2014, 54, 13-16. [CrossRef] 
190. Mañero, F.J.G.; Algar, E.; Martín Gómez, M.S.; Saco Sierra, M.D.; Solano, B.R. Elicitation of secondary metabolism in Hypericum perforatum by rhizosphere bacteria and derived elicitors in seedlings and shoot cultures. Pharm. Biol. 2012, 50, 1201-1209. [CrossRef]

191. Naik, P.M.; Al-Khayri, J.M. Abiotic and biotic elicitors-role in secondary metabolites production through in vitro culture of medicinal plants. In Abiotic and Biotic Stress in Plants-Recent Advances and Future Perspectives; Books on Demand: Norderstedt, Germany; Rijeka, Croatia, 2016; pp. 247-277.

192. Pauwels, L.; Inzé, D.; Goossens, A. Jasmonate-inducible gene: What does it mean? Trends Plant Sci. 2009, 14, 87-91. [CrossRef] [PubMed]

193. Krzyzanowska, J.; Czubacka, A.; Pecio, L.; Przybys, M.; Doroszewska, T.; Stochmal, A.; Oleszek, W. The effects of jasmonic acid and methyl jasmonate on rosmarinic acid production in Mentha $\times$ piperita cell suspension cultures. Plant Celltissue Organ Cult. 2012, 108, 73-81. [CrossRef]

194. Almagro, L.; Gutierrez, J.; Pedreño, M.A.; Sottomayor, M. Synergistic and additive influence of cyclodextrins and methyl jasmonate on the expression of the terpenoid indole alkaloid pathway genes and metabolites in Catharanthus roseus cell cultures. Plant Celltissue Organ Cult. 2014, 119, 543-551. [CrossRef]

195. Gangopadhyay, M.; Dewanjee, S.; Bhattacharya, S. Enhanced plumbagin production in elicited Plumbago indica hairy root cultures. J. Biosci. Bioeng. 2011, 111, 706-710. [CrossRef]

196. Belhadj, A.; Saigne, C.; Telef, N.; Cluzet, S.; Bouscaut, J.; Corio-Costet, M.-F.; Mérillon, J.-M. Methyl jasmonate induces defense responses in grapevine and triggers protection against Erysiphe necator. J. Agric. Food Chem. 2006, 54, 9119-9125. [CrossRef]

197. Tassoni, A.; Fornalè, S.; Franceschetti, M.; Musiani, F.; Michael, A.J.; Perry, B.; Bagni, N. Jasmonates and Na-orthovanadate promote resveratrol production in Vitis vinifera cv. Barbera cell cultures. New Phytol. 2005, 166, 895-906. [CrossRef]

198. Nopo-Olazabal, C.; Condori, J.; Nopo-Olazabal, L.; Medina-Bolivar, F. Differential induction of antioxidant stilbenoids in hairy roots of Vitis rotundifolia treated with methyl jasmonate and hydrogen peroxide. Plant Physiol. Biochem. 2014, 74, 50-69. [CrossRef]

199. Tassoni, A.; Durante, L.; Ferri, M. Combined elicitation of methyl-jasmonate and red light on stilbene and anthocyanin biosynthesis. J. Plant Physiol. 2012, 169, 775-781. [CrossRef] [PubMed]

200. Hao, X.; Shi, M.; Cui, L.; Xu, C.; Zhang, Y.; Kai, G. Effects of methyl jasmonate and salicylic acid on tanshinone production and biosynthetic gene expression in transgenic Salvia miltiorrhiza hairy roots. Biotechnol. Appl. Biochem. 2015, 62, 24-31. [CrossRef] [PubMed]

201. Sivanandhan, G.; Dev, G.K.; Jeyaraj, M.; Rajesh, M.; Arjunan, A.; Muthuselvam, M.; Manickavasagam, M.; Selvaraj, N.; Ganapathi, A. Increased production of withanolide A, withanone, and withaferin A in hairy root cultures of Withania somnifera (L.) Dunal elicited with methyl jasmonate and salicylic acid. Plant Celltissue Organ Cult. 2013, 114, 121-129. [CrossRef]

202. Sharma, P.; Yadav, S.; Srivastava, A.; Shrivastava, N. Methyl jasmonate mediates upregulation of bacoside A production in shoot cultures of Bacopa monnieri. Biotechnol. Lett. 2013, 35, 1121-1125. [CrossRef]

203. Sharma, S.N.; Jha, Z.; Sinha, R.K.; Geda, A.K. Jasmonate-induced biosynthesis of andrographolide in Andrographis paniculata. Physiol. Plant. 2015, 153, 221-229. [CrossRef]

204. Hayashi, H.; Huang, P.; Inoue, K. Up-regulation of soyasaponin biosynthesis by methyl jasmonate in cultured cells of Glycyrrhiza glabra. Plant Cell Physiol. 2003, 44, 404-411. [CrossRef]

205. Ketchum, R.E.; Tandon, M.; Gibson, D.M.; Begley, T.; Shuler, M. Isolation of labeled 9-dihydrobaccatin III and related taxoids from cell cultures of Taxus canadensis elicited with methyl jasmonate. J. Nat. Prod. 1999, 62, 1395-1398. [CrossRef]

206. Pedapudi, S.; Chin, C.K.; Pedersen, H. Production and elicitation of benzalacetone and the raspberry ketone in cell suspension cultures of Rubus idaeus. Biotechnol. Prog. 2000, 16, 346-349. [CrossRef]

207. Xu, A.; Zhan, J.-C.; Huang, W.-D. Effects of ultraviolet C, methyl jasmonate and salicylic acid, alone or in combination, on stilbene biosynthesis in cell suspension cultures of Vitis vinifera L. cv. Cabernet Sauvignon. Plant Celltissue Organ Cult. 2015, 122, 197-211. [CrossRef]

208. Idrees, M.; Naeem, M.; Aftab, T.; Khan, M.M.A. Salicylic acid mitigates salinity stress by improving antioxidant defence system and enhances vincristine and vinblastine alkaloids production in periwinkle [Catharanthus roseus (L.) G. Don]. Acta Physiol. Plant. 2011, 33, 987-999. [CrossRef]

209. Avancini, G.; Abreu, I.N.; Saldaña, M.D.; Mohamed, R.S.; Mazzafera, P. Induction of pilocarpine formation in jaborandi leaves by salicylic acid and methyljasmonate. Phytochemistry 2003, 63, 171-175. [CrossRef]

210. Bulgakov, V.; Tchernoded, G.; Mischenko, N.; Khodakovskaya, M.; Glazunov, V.; Radchenko, S.; Zvereva, E.; Fedoreyev, S.; Zhuravlev, Y.N. Effect of salicylic acid, methyl jasmonate, ethephon and cantharidin on anthraquinone production by Rubia cordifolia callus cultures transformed with the rolB and rolC genes. J. Biotechnol. 2002, 97, 213-221. [CrossRef]

211. Ali, M.B.; Yu, K.-W.; Hahn, E.-J.; Paek, K.-Y. Methyl jasmonate and salicylic acid elicitation induces ginsenosides accumulation, enzymatic and non-enzymatic antioxidant in suspension culture Panax ginseng roots in bioreactors. Plant Cell Rep. 2006, 25, 613-620. [CrossRef]

212. Shabani, L.; Ehsanpour, A.; Asghari, G.; Emami, J. Glycyrrhizin production by in vitro cultured Glycyrrhiza glabra elicited by methyl jasmonate and salicylic acid. Russ. J. Plant Physiol. 2009, 56, 621-626. [CrossRef]

213. Xu, Y.W.; Lv, S.S.; Zhao, D.; Chen, J.W.; Yang, W.T.; Wu, W. Effects of salicylic acid on monoterpene production and antioxidant systems in Houttuynia cordata. Afr. J. Biotechnol. 2012, 11, 1364-1372. 
214. Liang, Z.; Ma, Y.; Xu, T.; Cui, B.; Liu, Y.; Guo, Z.; Yang, D. Effects of abscisic acid, gibberellin, ethylene and their interactions on production of phenolic acids in Salvia miltiorrhiza Bunge hairy roots. PLoS ONE 2013, 8, e72806. [CrossRef] [PubMed]

215. Bertea, C.M.; Freije, J.; Van der Woude, H.; Verstappen, F.; Perk, L.; Marquez, V.; De Kraker, J.-W.; Posthumus, M.; Jansen, B.; De Groot, A. Identification of intermediates and enzymes involved in the early steps of artemisinin biosynthesis in Artemisia annua. Planta Med. 2005, 71, 40-47. [CrossRef]

216. Liu, Y.; Wang, H.; Ye, H.C.; Li, G.F. Advances in the plant isoprenoid biosynthesis pathway and its metabolic engineering. J. Integr. Plant Biol. 2005, 47, 769-782. [CrossRef]

217. Abbasi, B.H.; Stiles, A.R.; Saxena, P.K.; Liu, C.-Z. Gibberellic acid increases secondary metabolite production in Echinacea purpurea hairy roots. Appl. Biochem. Biotechnol. 2012, 168, 2057-2066. [CrossRef]

218. Yuan, Y.; Huang, L.-Q.; Cui, G.-H.; Mao, Y.; He, X.-R. Effect of gibberellins and its synthetic inhibitor on metabolism of tanshinones. Chin. J. Exp. Tradit. Medi-Cal Formulae 2008, 6, 2.

219. Banyai, W.; Mii, M.; Supaibulwatana, K. Enhancement of artemisinin content and biomass in Artemisia annua by exogenous GA 3 treatment. Plant Growth Regul. 2011, 63, 45-54. [CrossRef]

220. Yang, C.Q.; Fang, X.; Wu, X.M.; Mao, Y.B.; Wang, L.J.; Chen, X.Y. Transcriptional Regulation of Plant Secondary Metabolism F. J. Integr. Plant Biol. 2012, 54, 703-712. [CrossRef] [PubMed]

221. Phukan, U.J.; Jeena, G.S.; Shukla, R.K. WRKY transcription factors: Molecular regulation and stress responses in plants. Front. Plant Sci. 2016, 7, 760. [CrossRef]

222. Skibbe, M.; Qu, N.; Galis, I.; Baldwin, I.T. Induced plant defenses in the natural environment: Nicotiana attenuata WRKY3 and WRKY6 coordinate responses to herbivory. Plant Cell 2008, 20, 1984-2000. [CrossRef] [PubMed]

223. Ma, D.; Pu, G.; Lei, C.; Ma, L.; Wang, H.; Guo, Y.; Chen, J.; Du, Z.; Wang, H.; Li, G. Isolation and characterization of AaWRKY1, an Artemisia annua transcription factor that regulates the amorpha-4, 11-diene synthase gene, a key gene of artemisinin biosynthesis. Plant Cell Physiol. 2009, 50, 2146-2161. [CrossRef]

224. Yogendra, K.N.; Kumar, A.; Sarkar, K.; Li, Y.; Pushpa, D.; Mosa, K.A.; Duggavathi, R.; Kushalappa, A.C. Transcription factor StWRKY1 regulates phenylpropanoid metabolites conferring late blight resistance in potato. J. Exp. Bot. 2015, 66, 7377-7389. [CrossRef]

225. Kage, U.; Yogendra, K.N.; Kushalappa, A.C. TaWRKY70 transcription factor in wheat QTL-2DL regulates downstream metabolite biosynthetic genes to resist Fusarium graminearum infection spread within spike. Sci. Rep. 2017, 7, 42596. [CrossRef] [PubMed]

226. Karre, S.; Kumar, A.; Yogendra, K.; Kage, U.; Kushalappa, A.; Charron, J.-B. HvWRKY23 regulates flavonoid glycoside and hydroxycinnamic acid amide biosynthetic genes in barley to combat Fusarium head blight. Plant Mol. Biol. 2019, 100, 591-605. [CrossRef]

227. Vannozzi, A.; Wong, D.C.J.; Höll, J.; Hmmam, I.; Matus, J.T.; Bogs, J.; Ziegler, T.; Dry, I.; Barcaccia, G.; Lucchin, M. Combinatorial regulation of stilbene synthase genes by WRKY and MYB transcription factors in grapevine (Vitis vinifera L.). Plant Cell Physiol. 2018, 59, 1043-1059. [CrossRef]

228. Alfieri, M.; Vaccaro, M.C.; Cappetta, E.; Ambrosone, A.; De Tommasi, N.; Leone, A. Coactivation of MEP-biosynthetic genes and accumulation of abietane diterpenes in Salvia sclarea by heterologous expression of WRKY and MYC2 transcription factors. Sci. Rep. 2018, 8, 11009. [CrossRef] [PubMed]

229. Singh, A.K.; Kumar, S.R.; Dwivedi, V.; Rai, A.; Pal, S.; Shasany, A.K.; Nagegowda, D.A. A WRKY transcription factor from Withania somnifera regulates triterpenoid withanolide accumulation and biotic stress tolerance through modulation of phytosterol and defense pathways. New Phytol. 2017, 215, 1115-1131. [CrossRef]

230. Yogendra, K.N.; Dhokane, D.; Kushalappa, A.C.; Sarmiento, F.; Rodriguez, E.; Mosquera, T. StWRKY8 transcription factor regulates benzylisoquinoline alkaloid pathway in potato conferring resistance to late blight. Plant Sci. 2017, 256, 208-216. [CrossRef]

231. Fu, J.; Liu, Q.; Wang, C.; Liang, J.; Liu, L.; Wang, Q. ZmWRKY79 positively regulates maize phytoalexin biosynthetic gene expression and is involved in stress. J. Exp. Bot. 2017, 69, 497-510. [CrossRef] [PubMed]

232. Li, S.; Zhang, P.; Zhang, M.; Fu, C.; Yu, L. Functional analysis of a WRKY transcription factor involved in transcriptional activation of the DBAT gene in Taxus chinensis. Plant Biol. 2013, 15, 19-26. [CrossRef] [PubMed]

233. Chen, Q.; Chen, Z.; Lu, L.; Jin, H.; Sun, L.; Yu, Q.; Xu, H.; Yang, F.; Fu, M.; Li, S. Interaction between abscisic acid and nitric oxide in PB90-induced catharanthine biosynthesis of catharanthus roseus cell suspension cultures. Biotechnol. Prog. 2013, 29, 994-1001. [CrossRef] [PubMed]

234. Gonzalez, A.; Zhao, M.; Leavitt, J.M.; Lloyd, A.M. Regulation of the anthocyanin biosynthetic pathway by the TTG1/bHLH/Myb transcriptional complex in Arabidopsis seedlings. Plant J. 2008, 53, 814-827. [CrossRef]

235. Dubos, C.; Stracke, R.; Grotewold, E.; Weisshaar, B.; Martin, C.; Lepiniec, L. MYB transcription factors in Arabidopsis. Trends Plant Sci. 2010, 15, 573-581. [CrossRef] [PubMed]

236. Frerigmann, H.; Piślewska-Bednarek, M.; Sánchez-Vallet, A.; Molina, A.; Glawischnig, E.; Gigolashvili, T.; Bednarek, P. Regulation of pathogen-triggered tryptophan metabolism in Arabidopsis thaliana by MYB transcription factors and indole glucosinolate conversion products. Mol. Plant 2016, 9, 682-695. [CrossRef] [PubMed]

237. Liu, C.; Long, J.; Zhu, K.; Liu, L.; Yang, W.; Zhang, H.; Li, L.; Xu, Q.; Deng, X. Characterization of a citrus R2R3-MYB transcription factor that regulates the flavonol and hydroxycinnamic acid biosynthesis. Sci. Rep. 2016, 6, 25352. [CrossRef] 
238. Tian, W.-M.; Yang, S.-G.; Shi, M.-J.; Zhang, S.-X.; Wu, J.-L. Mechanical wounding-induced laticifer differentiation in rubber tree: An indicative role of dehydration, hydrogen peroxide, and jasmonates. J. Plant Physiol. 2015, 182, 95-103. [CrossRef]

239. Nisha, S.N.; Prabu, G.; Mandal, A.K.A. Biochemical and molecular studies on the resistance mechanisms in tea [Camellia sinensis (L.) O. Kuntze] against blister blight disease. Physiol. Mol. Biol. Plants 2018, 24, 867-880. [CrossRef]

240. Yamagishi, M.; Shimoyamada, Y.; Nakatsuka, T.; Masuda, K. Two R2R3-MYB genes, homologs of petunia AN2, regulate anthocyanin biosyntheses in flower tepals, tepal spots and leaves of Asiatic hybrid lily. Plant Cell Physiol. 2010, 51, 463-474. [CrossRef]

241. Wang, F.; Kong, W.; Wong, G.; Fu, L.; Peng, R.; Li, Z.; Yao, Q. AtMYB12 regulates flavonoids accumulation and abiotic stress tolerance in transgenic Arabidopsis thaliana. Mol. Genet. Genom. 2016, 291, 1545-1559. [CrossRef] [PubMed]

242. Onkokesung, N.; Reichelt, M.; van Doorn, A.; Schuurink, R.C.; van Loon, J.J.; Dicke, M. Modulation of flavonoid metabolites in Arabidopsis thaliana through overexpression of the MYB75 transcription factor: Role of kaempferol-3, 7-dirhamnoside in resistance to the specialist insect herbivore Pieris brassicae. J. Exp. Bot. 2014, 65, 2203-2217. [CrossRef] [PubMed]

243. Kishi-Kaboshi, M.; Seo, S.; Takahashi, A.; Hirochika, H. The MAMP-responsive MYB transcription factors MYB30, MYB55 and MYB110 activate the HCAA synthesis pathway and enhance immunity in Rice. Plant Cell Physiol. 2018, 59, 903-915. [CrossRef]

244. Wang, L.; Ran, L.; Hou, Y.; Tian, Q.; Li, C.; Liu, R.; Fan, D.; Luo, K. The transcription factor MYB115 contributes to the regulation of proanthocyanidin biosynthesis and enhances fungal resistance in poplar. New Phytol. 2017, 215, 351-367. [CrossRef] [PubMed]

245. Frerigmann, H.; Berger, B.; Gigolashvili, T. bHLH05 is an interaction partner of MYB51 and a novel regulator of glucosinolate biosynthesis in Arabidopsis. Plant Physiol. 2014, 166, 349-369. [CrossRef]

246. Zhang, H.; Hedhili, S.; Montiel, G.; Zhang, Y.; Chatel, G.; Pré, M.; Gantet, P.; Memelink, J. The basic helix-loop-helix transcription factor CrMYC2 controls the jasmonate-responsive expression of the ORCA genes that regulate alkaloid biosynthesis in Catharanthus roseus. Plant J. 2011, 67, 61-71. [CrossRef]

247. Nemesio-Gorriz, M.; Blair, P.B.; Dalman, K.; Hammerbacher, A.; Arnerup, J.; Stenlid, J.; Mukhtar, S.M.; Elfstrand, M. Identification of Norway spruce MYB-bHLH-WDR transcription factor complex members linked to regulation of the flavonoid pathway. Front. Plant Sci. 2017, 8, 305. [CrossRef]

248. Yamamura, C.; Mizutani, E.; Okada, K.; Nakagawa, H.; Fukushima, S.; Tanaka, A.; Maeda, S.; Kamakura, T.; Yamane, H.; Takatsuji, H. Diterpenoid phytoalexin factor, a bHLH transcription factor, plays a central role in the biosynthesis of diterpenoid phytoalexins in rice. Plant J. 2015, 84, 1100-1113. [CrossRef]

249. Todd, A.T.; Liu, E.; Polvi, S.L.; Pammett, R.T.; Page, J.E. A functional genomics screen identifies diverse transcription factors that regulate alkaloid biosynthesis in Nicotiana benthamiana. Plant J. 2010, 62, 589-600. [CrossRef] [PubMed]

250. Mertens, J.; Pollier, J.; Bossche, R.V.; Lopez-Vidriero, I.; Franco-Zorrilla, J.M.; Goossens, A. The bHLH transcription factors TSAR1 and TSAR2 regulate triterpene saponin biosynthesis in Medicago truncatula. Plant Physiol. 2016, 170, 194-210. [CrossRef] [PubMed]

251. Hong, S.-Y.; Roze, L.V.; Linz, J.E. Oxidative stress-related transcription factors in the regulation of secondary metabolism. Toxins 2013, 5, 683-702. [CrossRef] [PubMed]

252. Shaaban, M.I.; Bok, J.W.; Lauer, C.; Keller, N.P. Suppressor mutagenesis identifies a velvet complex remediator of Aspergillus nidulans secondary metabolism. Eukaryot. Cell 2010, 9, 1816-1824. [CrossRef]

253. Zhang, Y.; Xu, Z.; Ji, A.; Luo, H.; Song, J. Genomic survey of bZIP transcription factor genes related to tanshinone biosynthesis in Salvia miltiorrhiza. Acta Pharm. Sin. B 2018, 8, 295-305. [CrossRef] [PubMed]

254. An, J.-P.; Qu, F.-J.; Yao, J.-F.; Wang, X.-N.; You, C.-X.; Wang, X.-F.; Hao, Y.-J. The bZIP transcription factor MdHY5 regulates anthocyanin accumulation and nitrate assimilation in apple. Hortic. Res. 2017, 4, 17023. [CrossRef] [PubMed]

255. Zhou, F.; Sun, T.-H.; Zhao, L.; Pan, X.-W.; Lu, S. The bZIP transcription factor HY5 interacts with the promoter of the monoterpene synthase gene QH6 in modulating its rhythmic expression. Front. Plant Sci. 2015, 6, 304. [CrossRef] [PubMed]

256. Yoshida, Y.; Miyamoto, K.; Yamane, H.; Nishizawa, Y.; Minami, E.; Nojiri, H.; Okada, K. OsTGAP1 is responsible for JA-inducible diterpenoid phytoalexin biosynthesis in rice roots with biological impacts on allelopathic interaction. Physiol. Plant. 2017, 161, 532-544. [CrossRef] [PubMed]

257. Roze, L.V.; Chanda, A.; Wee, J.; Awad, D.; Linz, J.E. Stress-related transcription factor AtfB integrates secondary metabolism with oxidative stress response in aspergilli. J. Biol. Chem. 2011, 286, 35137-35148. [CrossRef]

258. Zhou, M.; Memelink, J. Jasmonate-responsive transcription factors regulating plant secondary metabolism. Biotechnol. Adv. 2016, 34, 441-449. [CrossRef]

259. Wasternack, C.; Song, S. Jasmonates: Biosynthesis, metabolism, and signaling by proteins activating and repressing transcription. J. Exp. Bot. 2017, 68, 1303-1321. [CrossRef]

260. Yu, Z.-X.; Li, J.-X.; Yang, C.-Q.; Hu, W.-L.; Wang, L.-J.; Chen, X.-Y. The jasmonate-responsive AP2/ERF transcription factors AaERF1 and AaERF2 positively regulate artemisinin biosynthesis in Artemisia annua L. Mol. Plant 2012, 5, 353-365. [CrossRef]

261. De Sutter, V.; Vanderhaeghen, R.; Tilleman, S.; Lammertyn, F.; Vanhoutte, I.; Karimi, M.; Inzé, D.; Goossens, A.; Hilson, P. Exploration of jasmonate signalling via automated and standardized transient expression assays in tobacco cells. Plant J. 2005, 44, 1065-1076. [CrossRef]

262. Shoji, T.; Hashimoto, T. Stress-induced expression of NICOTINE2-locus genes and their homologs encoding Ethylene Response Factor transcription factors in tobacco. Phytochemistry 2015, 113, 41-49. [CrossRef] [PubMed] 
263. Thagun, C.; Imanishi, S.; Kudo, T.; Nakabayashi, R.; Ohyama, K.; Mori, T.; Kawamoto, K.; Nakamura, Y.; Katayama, M.; Nonaka, S. Jasmonate-responsive ERF transcription factors regulate steroidal glycoalkaloid biosynthesis in tomato. Plant Cell Physiol. 2016, 57, 961-975. [CrossRef] [PubMed]

264. Deng, B.; Huang, Z.; Ge, F.; Liu, D.; Lu, R.; Chen, C. An AP2/ERF family transcription factor PnERF1 raised the biosynthesis of Saponins in Panax notoginseng. J. Plant Growth Regul. 2017, 36, 691-701. [CrossRef]

265. Guo, W.; Jin, L.; Miao, Y.; He, X.; Hu, Q.; Guo, K.; Zhu, L.; Zhang, X. An ethylene response-related factor, GbERF1-like, from Gossypium barbadense improves resistance to Verticillium dahliae via activating lignin synthesis. Plant Mol. Biol. 2016, 91, 305-318. [CrossRef] [PubMed]

266. Olsen, A.N.; Ernst, H.A.; Leggio, L.L.; Skriver, K. NAC transcription factors: Structurally distinct, functionally diverse. Trends Plant Sci. 2005, 10, 79-87. [CrossRef] [PubMed]

267. Saga, H.; Ogawa, T.; Kai, K.; Suzuki, H.; Ogata, Y.; Sakurai, N.; Shibata, D.; Ohta, D. Identification and characterization of ANAC042, a transcription factor family gene involved in the regulation of camalexin biosynthesis in Arabidopsis. Mol. Plant-Microbe Interact. 2012, 25, 684-696. [CrossRef] [PubMed]

268. Wu, H.; Fu, B.; Sun, P.; Xiao, C.; Liu, J.-H. A NAC transcription factor represses putrescine biosynthesis and affects drought tolerance. Plant Physiol. 2016, 172, 1532-1547. [CrossRef]

269. Duan, M.; Zhang, R.; Zhu, F.; Zhang, Z.; Gou, L.; Wen, J.; Dong, J.; Wang, T. A lipid-anchored NAC transcription factor is translocated into the nucleus and activates glyoxalase I expression during drought stress. Plant Cell 2017, 29, 1748-1772. [CrossRef] [PubMed]

270. Cao, Y.; Zhai, J.; Wang, Q.; Yuan, H.; Huang, X. Function of Hevea brasiliensis NAC1 in dehydration-induced laticifer differentiation and latex biosynthesis. Planta 2017, 245, 31-44. [CrossRef] [PubMed]

271. Mahmood, K.; Xu, Z.; El-Kereamy, A.; Casaretto, J.A.; Rothstein, S.J. The Arabidopsis transcription factor ANAC032 represses anthocyanin biosynthesis in response to high sucrose and oxidative and abiotic stresses. Front. Plant Sci. 2016, 7, 15. [CrossRef] [PubMed] 